\title{
CARACTERIZAÇÃO QUÍMICA DO NÚCLEO SUPRAQUIASMÁTICO DO PRIMATA Cebus apella
}

Dissertação apresentada ao Programa de PósGraduação em Ciências Morfofuncionais do Instituto de Ciências Biomédicas da Universidade de São Paulo, para obtenção do título de Mestre em Ciências. 


\section{CARACTERIZAÇÃo QUÍMICA DO NÚCLEO SUPRAQUIASMÁTICO DO PRIMATA Cebus apella}

Dissertação apresentada ao Programa de PósGraduação em Ciências Morfofuncionais do Instituto de Ciências Biomédicas, da Universidade de São Paulo, para obtenção do título de Mestre em Ciências.

Área de Concentração: Ciências Morfofuncionais

Orientadora:

Prof. Dra. Maria Inês Nogueira 
DADOS DE CATALOGAÇÃO NA PUBLICAÇÃO (CIP)

Serviço de Biblioteca e Informação Biomédica do

Instituto de Ciências Biomédicas da Universidade de São Paulo

reprodução não autorizada pelo autor

\section{Rocha, Vanderlei Amadeu.}

Caracterização química do núcleo supraquiasmático do primata Cebus apella / Vanderlei Amadeu Rocha. -- São Paulo, 2010.

Orientador: Maria Inês Nogueira.

Dissertação (Mestrado) - Universidade de São Paulo. Instituto de Ciências Biomédicas. Departamento de Anatomia. Área de concentração: Ciências Morfofuncionais. Linha de pesquisa: Ritmos Biológicos

Versão do título para o inglês: Neurochemical characterization of Cebus apella suprachiasmatic nucleus..

Descritores: 1. NSQ 2. Vasopressina 3. VIP 4. Ritmos biológicos 5.Primata 6. I. Nogueira, Maria Inês II. Universidade de São paulo. Instituto de ciências Biomédicas. Programa de Pós-Graduação em Departamento de Anatomia III. Título. 
Candidato(a):

Título da Dissertação:

Orientador(a):
Vanderlei Amadeu Rocha.

Caracterização química do núcleo supraquiasmático do primata Cebus apella .

A Comissão Julgadora dos trabalhos de Defesa da Dissertação de Mestrado, em sessão pública realizada a ./...................................,
( ) Aprovado(a)
( ) Reprovado(a)

Examinador(a): Assinatura:

Nome:

Instituição:

Examinador(a): Assinatura:

Nome:

Instituição:

Presidente: Assinatura:

Nome:

Instituição: 


\section{UNIVERSIDADE DE SÃO PAULO INSTITUTO DE CIÊNCIAS BIOMÉDICAS}

Cidade Universitária "Armando de Salles Oliveira"

Av. Prof. Lineu Prestes, 2415 - CEP. 05508-000 São Paulo, SP - Brasil

Telefone :(55) (011) 3091.7733 - telefax : (55) (011) 3091.7438

e-mail: cep@icb.usp.br

\section{Certificado}

Certificamos que o protocolo registrado sob $\mathrm{n}^{\circ} \mathbf{1 1 1}$ nas fls. $\mathbf{6 2}$ do livro $\mathbf{0 2}$ para uso de animais em experimentação, sob a responsabilidade de Maria Inês Nogueira, Coordenador(a) da Linha de pesquisa "Distribuição temporal $\boldsymbol{e}$ espacial do gene Per2 em áreas encefálicas do primata Cebus apella" do qual participou(aram) o(s) alunos Vanderlei Amadeu da Rocha $e$ os pesquisadores Jackson Cioni Bittencourt, Luciana Pinato está de acordo com os Princípios Éticos de Experimentação Animal adotado pelo Colégio Brasileiro de Experimentação Animal (COBEA) e foi aprovado pela COMISSÃO DE ÉTICA EM EXPERIMENTAÇÃO ANIMAL (CEEA) em 28.11.08, com validade de 3 anos.

São Paulo, 02 de dezembro de 2008.

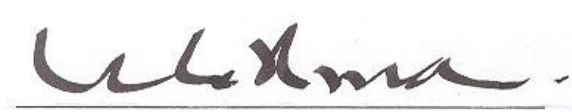

Prof. Dr. WOTHAN TAVARES DE LIMA Coordenador CEEA - ICB/USP

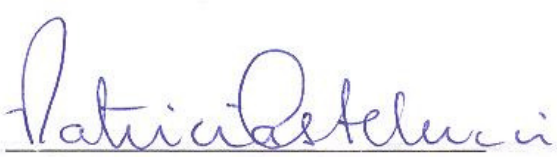

Profa. Dra. PATRÍcia CASTElucci

Secretária CEEA - ICB/USP 


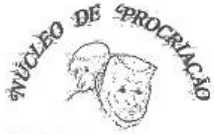

DE MACACOS- IPREGO
NUCIEODE PROCRIACÄO-DE MACACOS-PREGO Faculdade de Odontologia do Campus de Araçatuba Departamento de Ciências Básicas

\section{DECLARAÇÃO}

O presente tem como finalidade informar que o Núcleo de Procriação de Macacos-Prego do Departamento de Ciências Básicas da Faculdade de Odontologia do Campus de Araçatuba -UNESP, com base nas normativas de seu funcionamento (Portaria FOA 087/95) e as estabelecidas pelo IBAMA está de acordo com a realização do projeto de pesquisa "Distribuição temporal e espacial do gene Per2 em áreas encefálieas do primata Cebus apella", sob a responsabilidade da Prof. Vanderlei Amadeu da Rocha, orientado pela Profa. Dra. Maria Inệs Nogueira do Departamento de Anatomia - ICB - USP - SP.

Araçatuba, 17 de novembro de 2008.

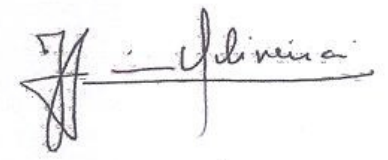

José Américo de Oliveira Responsável pelo Núcleo de Procriação de Macacos-Prego 
Dedico este trabalho aos meus pais, Antonio e Delzuita, e aо meu irmão, Vanderson, pelo apoio, incentivo, paciência e estímulo. 


\section{AGRADECIMENTOS}

À minha orientadora Profa. Dra. Maria Inês Nogueira, pela amizade e por todas as oportunidades de aprendizagem que muito contribuíram para a minha formação.

À Profa. Dra. Luciana Pinato, pela amizade, pelas discussões, pelo apoio, pela paciência e por ter me ensinado tanto nesses vários anos.

Aos amigos do laboratório: Paula, Wilma, Leila, Silvia, Cleyton, Renata Frazão, Renata Vasconcelos, Paola, Rômulo, Roberto, Barbara e Renné. Obrigado por participarem dessa etapa, cada um de uma forma única.

Aos professores do Departamento de Anatomia do Instituto de Ciências Biomédicas da Universidade de São Paulo, pela ajuda durante todo mestrado.

A todos os professores que abriram as portas de seus laboratórios e que viabilizaram o acontecimento desta pesquisa.

Ao Programa de Pós-graduação do Departamento de Anatomia do Instituto de Ciências Biomédicas da Universidade de São Paulo.

Ao Prof. Dr. Newton Canteras, coordenador do Programa de Pós-graduação do Departamento de Anatomia do Instituto de ciências Biomédicas da Universidade de São Paulo. 
Aos Professores, Jackson Bittencourt, Luciana Pinato e Newton Canteras, por terem constituído a banca do exame de qualificação e pela relevância das apreciações emitidas.

Aos Professores Doutores José Américo de Oliveira e Roelf Cruzz Rizzolo, do núcleo de Procriação de Macacos-Prego da UNESP.

Aos funcionários do Departamento de Anatomia do Instituto de Ciências Biomédicas da Universidade de São Paulo, pelo profissionalismo e competência nos serviços prestados.

Agradeço de forma especial aos meus pais e ao meu irmão, pelo amor incondicional, apoio constante e exemplo de luta, simplicidade, coragem e honestidade

A minha namorada Paula, exemplo de dedicação e perseverança, pelo companheirismo, por entender inúmeras vezes minha ausência e por dividir comigo todas as conquistas e angústias.

À Coordenadoria de Aperfeiçoamento de Pessoal de Ensino Superior (CAPES) pela concessão de bolsa para a realização deste Curso de Pós-Graduação

A todos aqueles que contribuíram de alguma maneira para a realização deste trabalho. 


\section{RESUMO}

Rocha VA. Caracterização química do núcleo supraquiasmático do primata Cebus apella. [dissertação (Mestrado em Ciências Morfofuncionais)]. São Paulo: Instituto de Ciências Biomédicas da Universidade de São Paulo; 2010.

O núcleo supraquiasmático (NSQ), principal relógio biológico circadiano em mamíferos, contem população variada de neurônios produtores de diferentes substâncias neuroativas. Estes tendem a formar grupos organizados que recebem as principais aferências do núcleo, o trato retinohipotalâmico, o trato geniculohipotalâmico e as projeções serotonérgicas da rafe. Em roedores, as pesquisas avançaram na investigação dos mecanismos moleculares e substâncias neuroativas, que em conjunto determinam a função do relógio biológico. Investigações sobre a presença e localização destas diferentes substâncias são essenciais não somente para o entendimento, mas também para o sucesso da manipulação do SCN como, por exemplo, com drogas terapêuticas e experimentais. Entretanto, há poucas informações em espécies diurnas, especialmente primatas sobre esta organização intrínseca que não raramente apresenta diferenças nas espécies estudadas. O presente estudo busca identificar a natureza química dos principais grupamentos neuronais do NSQ no primata diurno Cebus apella, relacionando a localização destes grupamentos com as três principais projeções aferentes deste núcleo. Os resultados obtidos evidenciam organização complexa do NSQ, caracterizada por grupos celulares contendo vasopressina (VP), polipeptídeo intestinal vasoativo (VIP) e marcador de diferenciação neural (NeuN) com localização semelhante a de roedores e células que contém calbindina e calretinina com localização diferente da de roedores.

Palavras-chave: NSQ. Vasopressina. VIP. Ritmos biológicos. Primata. 
Rocha VA. Neurochemical characterization of Cebus apella suprachiasmatic nucleus. [master thesis (Science Morphofunctional)]. São Paulo: Instituto de Ciências Biomédicas da Universidade de São Paulo; 2010.

The suprachiasmatic nucleus ( $\mathrm{SCN}$ ), the main circadian clock in mammals, contains diverse population of neurons of different neuroactive substances. These tend to form organized groups that receive major afferents from the nucleus, the retinohypothalamic tract, the tract geniculohipotalâmico and serotonergic raphe projections. In rodents, there has been extensive research in the recent past looking into the molecular basis and mechanisms of the biological clock. Investigations on the presence and location of these different substances are essential not only for understanding but also to the successful handling of the SCN, for example, with drugs and experimental therapies. However, there is little information in diurnal species, especially primates about this organization seldom has no intrinsic differences in the species studied. This study seeks to identify the chemical nature of the main groups of SCN neurons in diurnal primate Cebus apella, relating the location of these groups with the three major afferent projections from this nucleus. The results show complex organization of the SCN, characterized by cell groups containing vasopressin (VP), vasoactive intestinal polypeptide (VIP) and neuronal differentiation marker $(\mathrm{NeuN})$ in the same location and rodent cells that contain calbindin and calretinin with location different from that of rodents.

Keywords: SCN. Vasopressin. VIP. Biological rhythms. Primate. 


\section{LISTA DE ILUSTRAÇÕES}

Figura 1. Representação esquemática simplificada da organização do sistema circadiano nos mamíferos e os agentes sincronizadores dos NSQ e de alguns osciladores periféricos (glândula adrenal, coração, fígado e rins)

Figura 2. Esquema simplificado das vias de entrada fóticas para o NSQ em roedores

Figura 3. Desenho esquemático de cortes coronais do encéfalo do Macaco-prego (Cebus apella) ilustrando a localização do núcleo no hipotálamo

Figura 4. Fotografia do Macaco-prego (Cebus apella)

Figura 5. Em A e B, organização dos corpos de neurônios e fibras imunorreativas a calbindina (CalB-IR) no NSQ do Cebus apella em fotomicrografias de cortes coronais ao longo do eixo ântero-posterior em microscopia de campo claro e desenhos esquemáticos ilustrando a organização destes corpos de neurônios (C e D). $3 \mathrm{~V}$ = terceiro ventrículo; $\mathrm{OX}=$ quiasma óptico. Escala: $200 \mu \mathrm{m}$.

Figura 6. Em A e B, organização dos corpos de neurônios e fibras imunorreativas a calretinina (CalR-IR) no NSQ do Cebus apella em fotomicrografias de cortes coronais ao longo do eixo ântero-posterior em microscopia de campo claro e desenhos esquemáticos ilustrando a organização destes corpos de neurônios ( $\mathrm{C}$ e D). $3 \mathrm{~V}=$ terceiro ventrículo; $\mathrm{OX}=$ quiasma óptico. Escala: $200 \mu \mathrm{m}$. 
Figura 7. Em A e B, organização das fibras imunorreativas a 5H-T(5H-T-IR) no NSQ do Cebus apella em fotomicrografias de cortes coronais ao longo do eixo ântero-posterior em microscopia de campo claro e desenhos esquemáticos ilustrando a distribuição das fibras (C e D). $3 \mathrm{~V}=$ terceiro ventrículo; $\mathrm{OX}=$ quiasma óptico. Escala: $200 \mu \mathrm{m} . . . \ldots . .$.

Figura 8. Em A e $B$, organização dos corpos de neurônios e fibras imunorreativas a VIP-IR no NSQ do Cebus apella em fotomicrografias de cortes coronais ao longo do eixo ânteroposterior em microscopia de campo claro e desenhos esquemáticos ilustrando o padrão de fibras $(\mathrm{C}$ e $\mathrm{D}) .3 \mathrm{~V}=$ terceiro ventrículo; $\mathrm{OX}=$ quiasma óptico. Escala: $200 \mu \mathrm{m}$

Figura 9. Em A e B, organização dos corpos de neurônios e fibras imunorreativas a VIP-IR no NSQ do Cebus apella em fotomicrografias de cortes coronais ao longo do eixo ânteroposterior em microscopia de campo claro e desenhos esquemáticos ilustrando a organização destes corpos de neurônios (C e D). $3 \mathrm{~V}=$ terceiro ventrículo; OX = quiasma óptico. Escala: $200 \mu \mathrm{m}$

Figura 10. Em A e B, organização dos corpos de neurônios e fibras imunorreativas NeuN (Neun-IR) no NSQ do Cebus apella em fotomicrografias de cortes coronais ao longo do eixo ânteroposterior em microscopia de campo claro e desenhos esquemáticos ilustrando a distribuição da Neun-IR (C e D). 3V = terceiro ventrículo; OX = quiasma óptico. Escala: $200 \mu \mathrm{m}$.

Figura 11. Em A e B, organização dos corpos de neurônios e fibras imunorreativas a vasopressina (VP-IR) no NSQ do Cebus apella em fotomicrografias de cortes coronais ao longo do eixo ânteroposterior em microscopia de campo claro e desenhos esquemáticos ilustrando a organização dos corpos de neurônios e fibras VP-IR (C 
e D). $3 \mathrm{~V}=$ terceiro ventrículo; $\mathrm{OX}=$ quiasma óptico. Escala: 200 $\mu \mathrm{m}$

Figura 12. Fotomicrografias de cortes coronais ao longo do eixo ântero-posterior em microscopia de campo claro no NSQ do Cebus apella. Em A, B, C organização dos corpos de neurônios e fibras imunorreativas a calbindina (CalB-IR); Em D, E, F organização dos corpos de neurônios e fibras imunorreativas a calretinina (CalR-IR); Em G, H, I organização das fibras imunorreativas a 5H-T (5H-T-IR); Em J, K, L organização dos corpos de neurônios e fibras imunorreativas a VIP (VIP-IR); Em M, N, O organização dos corpos de neurônios e fibras imunorreativas NeuN (Neun-IR); Em P, Q, R organização dos corpos de neurônios e fibras imunorreativas a vasopressina (VP-IR). $3 \mathrm{~V}=$ terceiro ventrículo; $\mathrm{OX}=$ quiasma óptico

Figura 13. Desenhos esquemáticos do NSQ de Cebus Apella demonstrando os diferentes grupos de células imunorreativas com as principais terminações aferentes: Calbindina, calretinina, 5-HT, VIP e Neun. 3V $=$ terceiro ventrículo; OX = quiasma óptico. Escala: $200 \mu \mathrm{m}$.

Figura 14. Fotomicrografias em fluorescência de cortes coronais ao longo do eixo ântero-posterior do NSQ do Cebus apella. Em A, B, C, D organização dos corpos de neurônios e fibras imunorreativas a vasopressina (VPIR); Em E, F, G, H distribuição das projeções retinianas por imunorreatividade ao anticorpo contra a toxina colérica subunidade B (CTb-IR); Em I, J, K, L mostram a sobreposição dos corpos de neurônios imunorreativos a vasopressina e $\mathrm{CTb} .3 \mathrm{~V}=$ terceiro ventrículo; $\mathrm{OX}=$ quiasma óptico. 
Figura 15. Fotomicrografias em fluorescência de cortes coronais ao longo do eixo ântero- posterior do NSQ do Cebus apella. Em A, B, C organização dos corpos de neurônios e fibras imunorreativas a vasopressina (VPIR); Em D, E, F organização dos corpos de neurônios e fibras imunorreativas NeuN (Neun-IR); Em G, H, I co-localização dos corpos de neurônios imunorreativas a vasopressina e NeuN $.3 \mathrm{~V}=$ terceiro ventrículo; $\mathrm{OX}=$ quiasma óptico.

Figura 16. Desenho esquemático do NSQ de Cebus Apella demonstrando a sobreposição dos diferentes grupos de células imunorreativas: calbindina, calretinina, Neun, 5-HT, VIP e VP. $3 \mathrm{~V}=$ terceiro ventrículo; $\mathrm{OX}=$ quiasma óptico.

Figura 17. Desenho esquemático do NSQ de Cebus Apella demonstrando a sobreposição dos diferentes grupos de células imunorreativas: calbindina, calretinina, Neun, 5-HT, VIP e VP. 3V = terceiro ventrículo; $\mathrm{OX}=$ quiasma óptico 


\begin{tabular}{|c|c|}
\hline $3 \mathbf{V}$ & terceiro ventrículo \\
\hline 5-HT & serotonina \\
\hline 5-HT-IR & imunorreatividade a serotonina \\
\hline CalB & calbindina \\
\hline CalB-IR & imunorreativas à calbindina \\
\hline CalR & calretinina \\
\hline CalR-IR & imunorreativas a calretinina \\
\hline $\mathbf{C E}$ & claro-escuro \\
\hline $\mathbf{C T b}$ & toxina colérica subunidade $\mathrm{B}$ \\
\hline CTb-IR & imunorreatividade a CTb \\
\hline GABA & ácido gama aminobutírico \\
\hline GLU & glutamato \\
\hline GRP & peptídeo liberador de gastrina \\
\hline IGL & folheto intergeniculado \\
\hline NeuN & proteína nuclear neuronal específica \\
\hline NeuN-IR & imunorreatividade a NeuN \\
\hline NPY & neuropeptídeo Y \\
\hline NPY-IR & neuropeptídeo Y imunoreativos \\
\hline NSQ & núcleo supraquiasmático \\
\hline $\mathbf{O X}$ & quiasma óptico \\
\hline PBS & tampão fosfato \\
\hline PGN & núcleo pré-geniculado \\
\hline TGH & trato geniculohipotalâmico \\
\hline TRH & trato retinohipotalâmico \\
\hline VIP & polipeptídeo intestinal vasoativo \\
\hline VIP-IR & imunorreativos ao VIP \\
\hline VP & vasopressina \\
\hline VP-IR & imunorreativas a vasopressina \\
\hline
\end{tabular}


1 INTRODUÇÃ

1.1 Ritmicidade biológica................................................................. 17

1.2 Núcleo Supraquiasmático............................................................. 20

1.3 O Macaco-prego como modelo experimental ................................... $\quad 24$

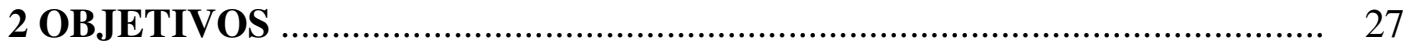

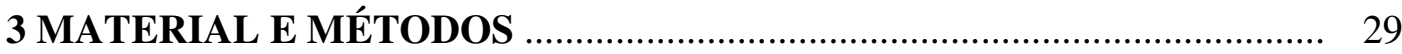

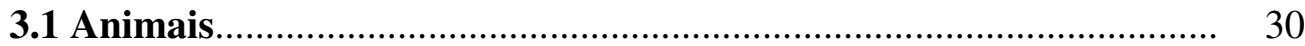

3.2 Imunoistoquímica .................................................................. 30

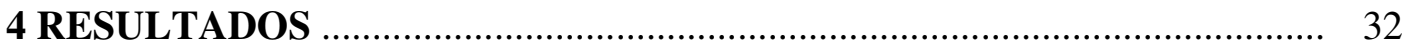

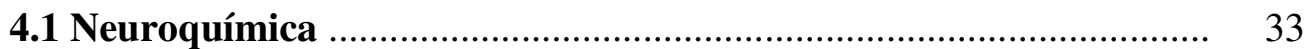

4.2 Sobreposição dos diferentes grupos de células imunorreativas com as principais terminações aferentes .......................................... 44

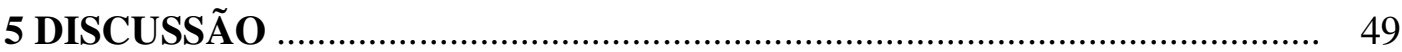

5.1 Organização dos grupos celulares no NSQ …............................... 50

5.2 Colocalização dos corpos neuronais com as principais terminações aferentes................................................................. 53

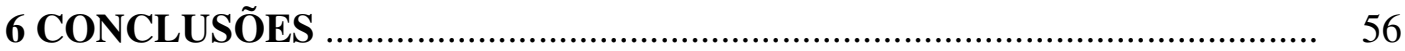

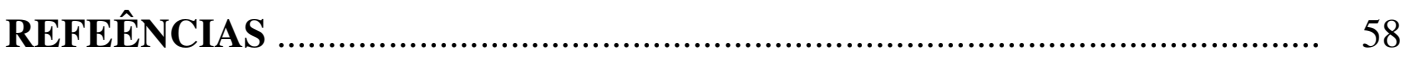




\subsection{Ritmicidade biológica}

A cronobiologia, ciência que investiga as características temporais dos organismos vivos (Halberg, 1969), inclui o estudo dos ritmos biológicos caracterizados pela recorrência, a intervalos regulares, de eventos bioquímicos, fisiológicos e comportamentais (Aschoff, 1965).

Inúmeros fenômenos biológicos apresentam ritmicidade na maioria dos organismos vivos, tais como ciclo vigília/sono, secreção de hormônios, freqüência cardíaca, pressão arterial, temperatura corporal, desempenho psicomotor e percepção, entre outros, nos diferentes níveis de organização (Moore et al., 1982). Os fenômenos fisiológicos que possuem oscilação com período em torno de $24 \mathrm{~h}$, são chamados ritmos circadianos, característica encontrada em quase todos os organismos vivos (Marques e Menna-Barreto, 2003).

Além da oscilação ao redor de 24 horas, outra característica dos ritmos circadianos é sua persistência mesmo na ausência de pistas temporais (Aschoff, 1965). A persistência da ritmicidade biológica, como por exemplo, do ritmo de atividade/repouso, em ambientes mantidos constantes, é uma das evidências do caráter endógeno destes ritmos biológicos, isto é, do fato destes serem determinados por fatores internos do organismo podendo ser influenciados por fatores externos, propiciando assim, adaptação individual efetiva.

Há algum tempo, as pesquisas na área da fisiologia evidenciaram a existência de um sistema temporizador que gera e sincroniza os diferentes ritmos circadianos (Moore, 1997). Para que o organismo ajuste os seus ritmos aos ciclos ambientais, ele necessita de informações tanto externas quanto internas, que atuem como pistas temporais. Essas duas informações, de diferentes origens (exógena e endógena), são recebidas e transmitidas até o principal oscilador biológico interno, situado no núcleo supraquiasmático (NSQ) do hipotálamo (Menaker, 2003). O NSQ sinaliza para os diferentes órgãos efetores, que podem ser: coração, pulmões, rins, fígado, músculos, etc. A interação desse complexo: receptor integrador - efetores caracteriza o sistema de temporização circadiana. 
Em mamíferos, o sistema de temporização circadiana está organizado como uma hierarquia de osciladores, composta por um oscilador central "dominante", o NSQ do hipotálamo, e por osciladores periféricos "submissos", que aos poucos vêm sendo reconhecidos (glândula adrenal, coração, fígado e rins) (Dunlap et al., 2004) (Figura 1).

Os ritmos circadianos podem ser sincronizados pelo ciclo de luz ambiental e ou por estímulos não fóticos (Green e Gillete, 1982; Inouye e Kawamura, 1979; Johnson et al., 1988; Lehman et al., 1987; Newman e Hospod, 1986; Ralph et al., 1990). Em roedores, por exemplo, a informação fótica é enviada ao NSQ por projeções diretas da retina via trato retinohipotalâmico (TRH) e por via indireta pelo trato geniculohipotalâmico (TGH) formado pela via: retina - folheto itergeniculado (IGL) - NSQ. Há ainda a possibilidade, de o NSQ ser sincronizado também pela via: retina - rafe - NSQ descrita em algumas espécies, inclusive em macacos-prego (Fite e Janusonis, 1999; Frazão et al., 2008; Shen e Semba, 1994) (Figura 2).

A existência da principal via sincronizadora deste sistema, o trato retinohipotalâmico $(\mathrm{TRH})$, foi confirmada em estudos realizados em várias espécies de mamíferos, incluindo primatas do Velho e do Novo mundo (Hendrickson et al., 1972; Moore e Lenn, 1972; Moore, 1973, 1993; Costa et al., 1999; Cavalcante, 2000).

As descrições originais do TRH, baseadas em técnicas de auto-radiografia, descrevem projeções da retina, no hipotálamo, exclusivamente para o NSQ (Hendrickson et al., 1972; Moore, 1973), entretanto, a utilização de traçadores neurais mais sensíveis, tais como toxina colérica, tornou evidente a existência de projeções para outras regiões do hipotálamo como, por exemplo, para área pré-óptica medial, área pré-óptica lateral, núcleo pré-óptico mediano, núcleo paraventricular, área hipotalâmica anterior, área hipotalâmica lateral, núcleo supra-óptico, área retroquiasmática e zona subparaventricular (Levine et al., 1991; Youngstrom, Weiss e Nunez, 1991; Moore, 1993; Costa et al., 1999; Cavalcante, 2000). 


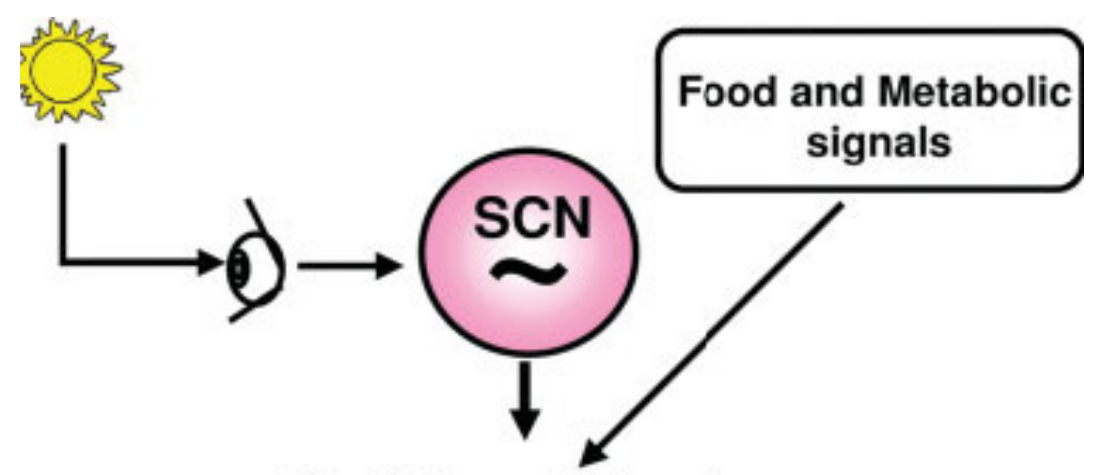

\section{Peripheral Clocks}

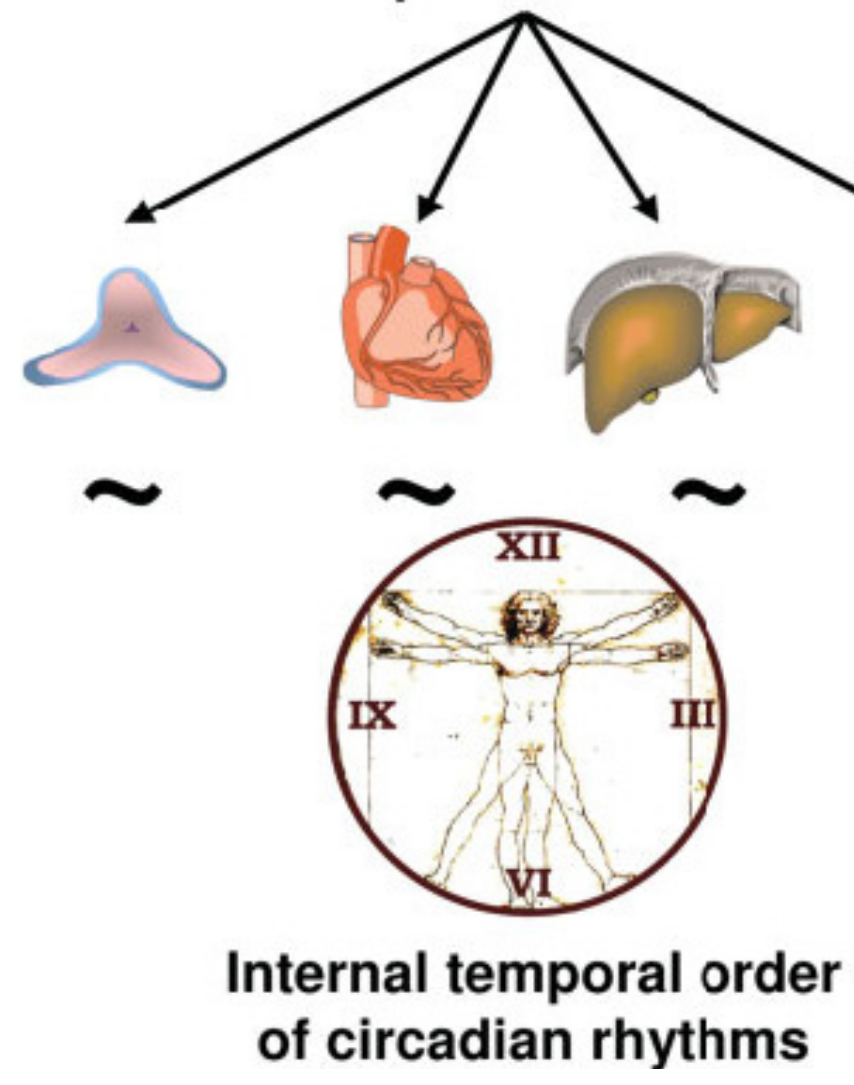

Figura 1. Representação esquemática simplificada da organização do sistema circadiano nos mamíferos e os agentes sincronizadores dos NSQ e de alguns osciladores periféricos (glândula adrenal, coração, fígado e rins). O NSQ é sincronizado, dentre outras pistas, pelo ciclo claro-escuro (CE), e os relógios periféricos através de sinais neurais e hormonais e pelo próprio NSQ. Alimentação e sinais metabólicos também contribuem para a sincronização dos relógios periféricos.

Fonte: Adaptado de Ferre (2007). 


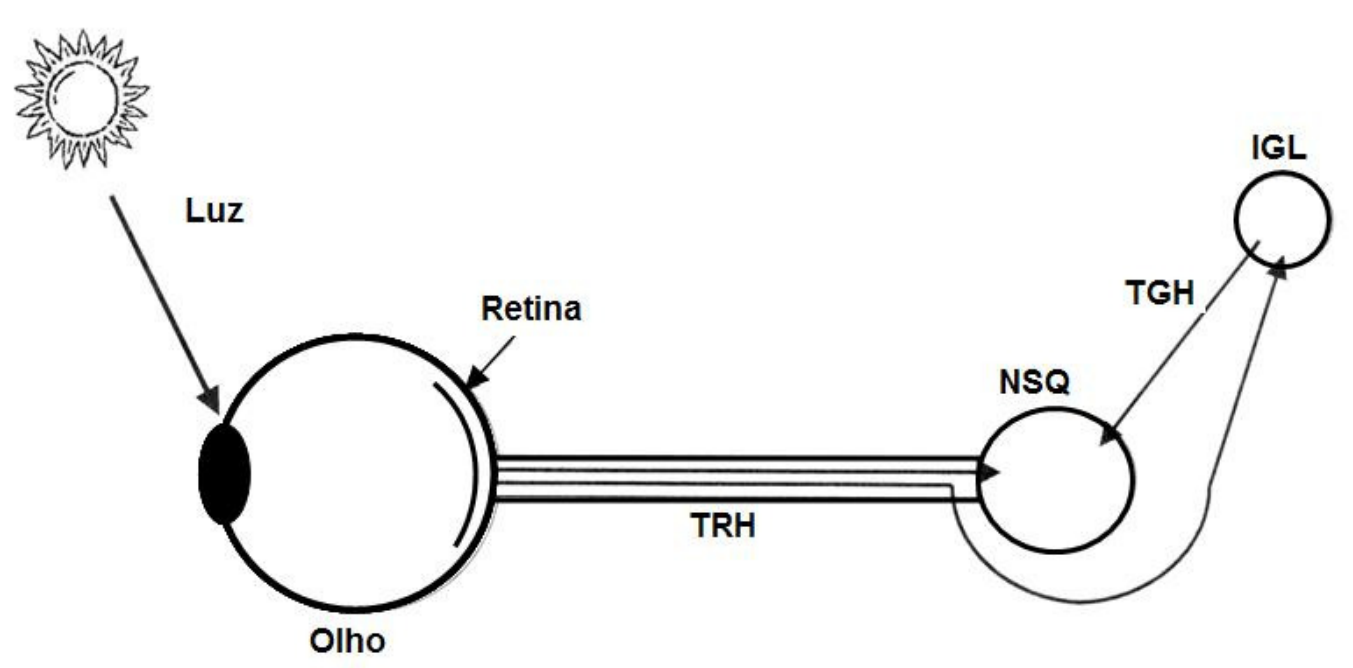

Figura 2. Esquema simplificado das vias de entrada fóticas para o NSQ em roedores. O ciclo claroescuro ambiental é detectado pelas células ganglionares da retina. As informações fóticas são transmitidas para os NSQ por duas vias principais. A primeira via, direta, conecta a retina ao NSQ, a segunda indireta, conecta a retina ao folheto intergeniculado (IGL), o qual por sua vez conecta-se ao NSQ via trato geniculohipotalâmico (TGH). Há ainda uma terceira via, que conecta primeiramente a retina com a rafe, a qual por sua vez conecta-se ao IGL e ao NSQ.

Fonte: Adaptado de Sehgal (2004).

\subsection{Núcleo Supraquiasmático}

O núcleo supraquiasmático (NSQ) do hipotálamo é o local do principal marcapasso circadiano em mamíferos (Stephan e Zucker, 1972; Moore e Lenn, 1972; Hendrickson et al., 1972; Ralph et al., 1990; Moore e Leak, 2001) (Figura 3). Múltiplas células que estão presentes neste relógio circadiano podem, quando sincronizadas, coordenar e regular diferentes ritmos. Estas células não compõem um grupo homogêneo, ao invés disto diferentes tipos de células, possuem diferentes funções dentro do NSQ dependendo do seu fenótipo e/ou localização (Schaap et al., 2001; Saeb-Parsy e Dyball, 2003; Quintero et al., 2003; Hamada et al., 2004). Isso aumenta a ênfase no conhecimento da organização intrínseca do NSQ já que tal organização pode ter implicações na regulação funcional do sistema de temporização circadiano. Evidências que indicam a co-localização de alguns dos neurotransmissores no NSQ complicou ainda mais as investigações sobre o papel dos 
neurotransmissores no funcionamento do relógio. É provável que o funcionamento do relógio possa depender da presença de um neurotransmissor específico em um mecanismo em que neurotransmissores co-localizados interajam de uma maneira funcionalmente significativa.

Em várias espécies de mamíferos já estudados, o NSQ pode ser dividido anatomicamente e funcionalmente em duas subdivisões distintas, a região ventrolateral, também chamada de core NSQ e a região dorsomedial também chamada de shell NSQ (Van den Pol, 1980; Moore, 1983, 1995). A subdivisão ventrolateral do NSQ contêm principalmente o campo de aferência do trato retinohipotalâmico (TRH), o qual transmite informação fótica das células ganglionares da retina que contêm melanopsina (Berson et al., 2002) para os neurônios imunoreativos ao polipeptídeo intestinal vasoativo (VIP). Em adição, uma população de neurônios imunorreativas à calbindina está localizado em uma subregião, e estes neurônios parecem ser necessários para a manutenção dos ritmos circadianos (LeSauter e Silver,1999). A subdivisão dorsomedial do NSQ não recebe inervação fótica direta do TRH, porém recebe esta inervação indiretamente via projeções da área ventrolateral para a dorsomedial do NSQ (Albus et al., 2005). O principal neuropeptideo expresso na subdivisão dorsomedial do NSQ, é a vasopressina (VP), sendo esta característica conservada em todas espécies de mamíferos já estudada. Outros neuropeptideos são também expressos na região dorsomedial do NSQ, entretanto ao contrario da VP, estes costumam variar quando a presença e ou localização entre as espécies estudadas como a Calretinina (Leak e Moore, 2001), somatostatina (Tominaga et al., 1992) e outros neuropeptideos. 

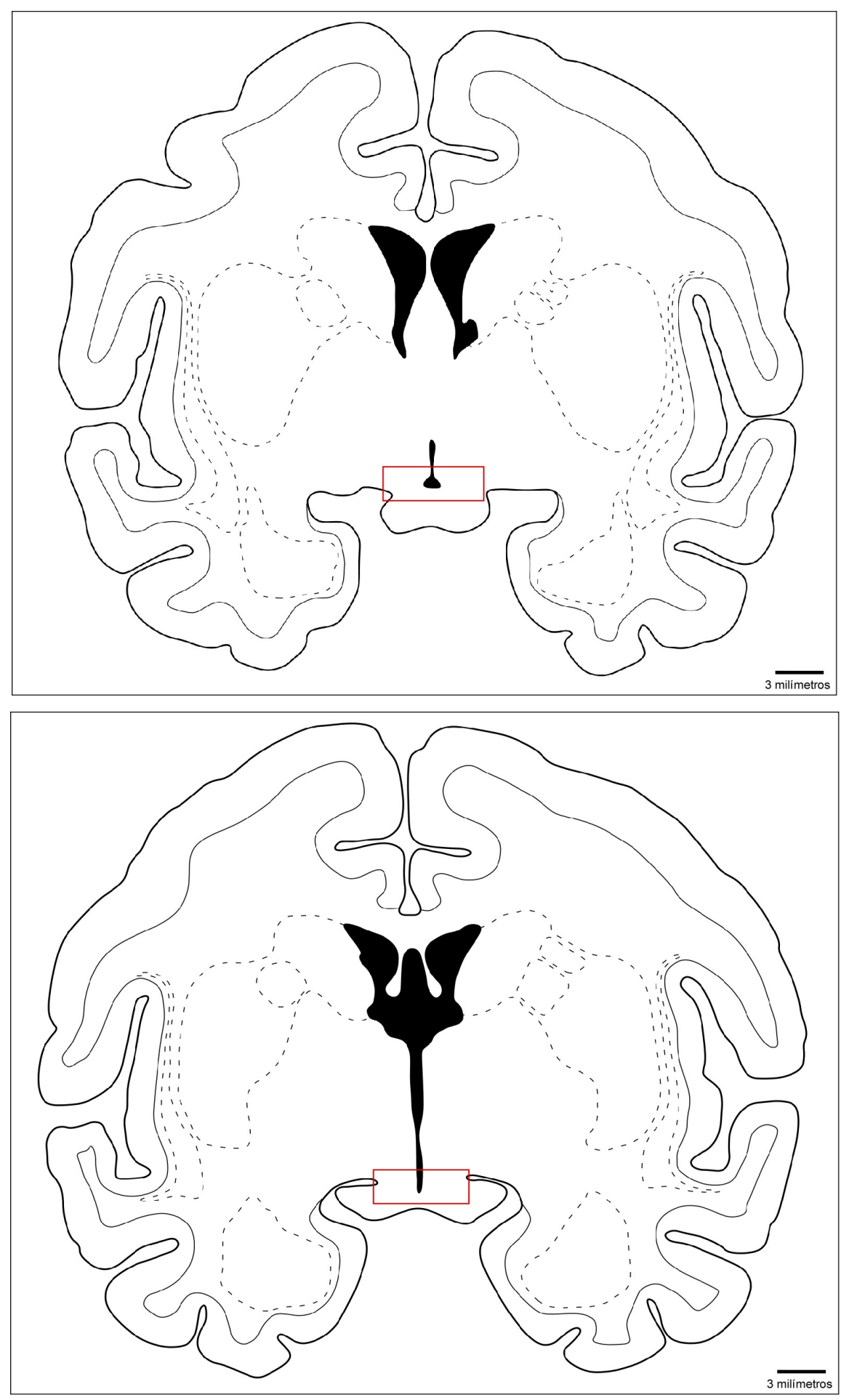

Figura 3. Desenho esquemático de cortes coronais do encéfalo do Macacoprego (Cebus apella) ilustrando a localização do NSQ no hipotálamo. 
Embora ainda utilizada, esta idéia de uma divisão simplificada em duas subdivisões dentro do núcleo foi recentemente contestada (Morin et al., 2006; Morin, 2007), baseada no fato de haver sobreposições entre os grupos de diferentes identidades neuroquímicas (Goel et al., 1999; Morin et al., 2006), pela existência de expressões rítmicas na expressão das substâncias neuroativas, pelo NSQ comportar-se como um sistema e ter interações entre seus constituintes celulares, além das variações dos padrões de expressão destes constituintes entre espécies (Morin et al., 1992; Miller et al., 1996; Silver et al., 1996b; LeSauter et al., 2002).

A co-localização de alguns destes neurotransmissores no NSQ só aumenta a complexidade desta organização intrínseca cujo conhecimento detalhado requer estudos temporais e comparativos principalmente entre espécies diurnas e noturnas. Isto se justifica já que tal organização pode ter implicações na regulação funcional do sistema de temporização circadiano.

Entre roedores e primatas, os principais parâmetros de distinção entre as espécies já estudadas estão na distribuição das três principais aferências ao NSQ: o trato retinohipotalâmico (TRH); o trato geniculohipotalâmico (TGH) e as projeções serotonérgicas da rafe que apresentam semelhanças entre roedores (Muscat et al., 2003; Morin et al., 2003; Kaas e Huerta, 1988; Moore, 1989) e diferenças entre roedores e primatas (Pinato et al., 2007; Costa et al., 1999; Cavalcante et al., 2002; Chevassus- auLouis, 1998; Murakami e Fuller, 1990; More e Speh, 2004).

Apesar da existência de diferenças interespecíficas, como por exemplo, quanto à presença ou ausência de uma série de peptídeos contidos nas células no NSQ, bem como as distribuições e o grau de sobreposição entre estas populações de células fenotipicamente distintas (Goel et al., 1999; Morin et al., 2006), há algumas similaridades na morfologia do NSQ compartilhada por roedores. As mais evidentes são as populações de neurônios contendo vasopressina (VP) e de peptídeo intestinal vasoativo (VIP) nas porções dorsomedial e ventral do NSQ respectivamente (Moore et al., 2002; Morin e Allen, 2005). 
A organização intrínseca do NSQ foi pouco explorada em espécies de primatas. Quanto à aferencias, no Cebus apella as projeções serotonérgicas encontram-se distribuídas pela periferia do NSQ, com poucas terminações na região central (Pinato et al., 2007). No marmosete Calithrix jacchus o TRH projeta-se bilateralmente (Costa et al., 1999) e os terminais NPY localizam-se principalmente na parte ventral do NSQ enquanto os serotonérgicos localizam-se principalmente nas regiões central e dorsal (Cavalcante et al., 2002). Algumas espécies de primatas aparentemente não possuem terminações NPY no NSQ (Chevassus- au- Louis, 1998). No squirrel Monkey e no Bonnet Macaque a projeção é bilateral sem diferença de densidade entre os lados ipso e contra lateral (Murakami e Fuller, 1990). More e Speh (2004) mostram que a há uma inervação serotoninérgica densa no NSQ de macacos e humanos, que é muito semelhante em densidade e padrão do que é observado em roedores.

\subsection{O Macaco-prego como modelo experimental}

O Cebus apella pertence ao filo Chordata, classe Mammalia, ordem Primates, família Cebidae e gênero Cebus (Oppenheimer, 1968), cujo nome popular é macaco prego (devido ao formato da glande achatada) (Figura 4).

Geograficamente distribuídos por quase todo o Brasil, os macacos-prego vivem em florestas neotropicais, como a Floresta Amazônica, assim como em áreas de cerrado e caatinga (Bicca-Marques et al., 2006) e, adaptam-se bem à vida em cativeiro, onde se reproduzem com facilidade (Hill, 1962). Seu tamanho, da cabeça ao final do corpo, varia de 30 a 56cm; sua cauda mede entre 30 a $55 \mathrm{~cm}$; e $3,5 \mathrm{~kg}$ de peso. Possuem cauda preênsil, utilizando-a como um membro auxiliar na locomoção. 


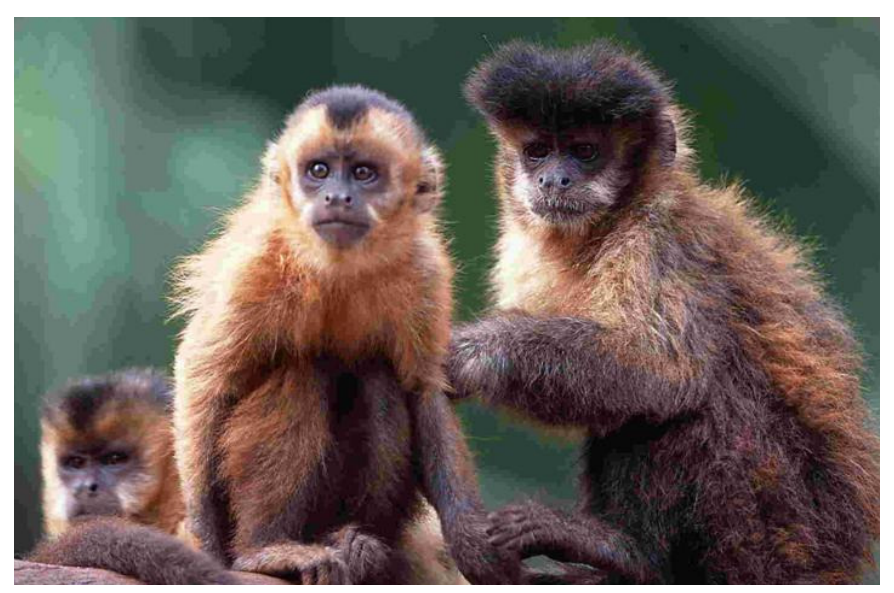

Figura 4. Fotografia do Macaco-prego (Cebus apella).

É uma espécie diurna e, devido a sua grande agilidade, locomove-se constantemente entre as árvores, vivendo no dossel e descendo ocasionalmente no chão para forragear, apresentando uma dieta eclética, que consiste principalmente de frutos e insetos, mas ainda de sementes, flores e pequenos vertebrados, sendo especialmente adaptável ao meio em que vive (Mittermeier e Coimbra Filho, 1977; Mittermeier, 1982).

Os macacos-prego vivem em sociedades hierárquicas onde em geral é um macho adulto que comanda o bando, sendo que, às vezes o grupo tem mais fêmeas que machos. As fêmeas têm normalmente um filhote pôr vez, depois de uma gestação de aproximadamente 6 meses, este fica preso no peito da mãe depois de nascer, passando depois de algum tempo para as costas. O recém nascido é cuidado por todos os indivíduos da comunidade, implicando em transporte, partilha de alimento, catação e amamentação comunal (Verderane et al., 2005).

Segundo Carthy e Howse (1980), a hierarquia numa sociedade de primatas garante uma cooperação pacífica entre esses animais e tal comportamento é "aprendido" na infância e adolescência durante as interações e brincadeiras com macacos jovens, nas quais além de desenvolver suas habilidades motoras, também se familiarizam com indivíduos da sociedade. 
O macaco prego, em particular, é considerado muito inteligente devido ao uso de ferramentas, que ocorre principalmente para alimentação, forrageamento, para proteger-se da predação e, para cuidar de si mesmo e de outros indivíduos do grupo. 
O objetivo do presente estudo é fornecer dados sobre as sobreposições das distribuições espaciais dos vários tipos de células, dentro do NSQ, e suas relações com os principais campos terminais aferentes deste núcleo, no primata Cebus apella. 


\subsection{Animais}

Para este estudo foram utilizados cortes encefálicos de macacos machos adultos da espécie, Cebus apella, (pesando de 2 a $3 \mathrm{~kg}$ ) provenientes do Núcleo de Procriação de Macacos Prego da Universidade Estadual Paulista "Júlio de Mesquita Filho", AraçatubaSP, Brazil, mantidos em gaiolas individuais sob condições naturais de umidade, temperatura e ciclo de iluminação (início do dia por volta das $6 \mathrm{~h}$ e anoitecer por volta das 18h) e alimentação padronizada com frutas e vegetais. Os procedimentos relativos à manipulação e confinamento dos animais atendem às disposições básicas contidas no "Guide to the Care and Use of Experimental Animals", v. 1 e 2, do Canadian Council on Animal Care, bem como a normativas dispostas na Portaria 016/94 do IBAMA, obedecem também ao Guidelines for the care and use of mammals in neuroscience and behavioral research (2003) e foram aprovados pela comissão local de ética no uso de animais de laboratório.

Os animais foram anestesiados e perfundidos transcardíacamente. As perfusões foram realizadas no período entre $9 \mathrm{~h}$ e $11 \mathrm{~h}$ da manhã. Os encéfalos foram removidos e crioprotegidos. Sendo, posteriormente crioseccionados em criostato em cortes de $40 \mu \mathrm{m}$ de espessura, coletados em 10 séries e estocados em solução anti-congelante até o momento da reação imunoistoquímica. Algumas séries foram utilizadas para as reações do presente estudo, outras foram utilizadas em outros estudos e ainda a comparação com os terminais aferentes foi feita utilizando-se lâminas preparadas em estudos anteriores de nosso laboratório.

\subsection{Imunoistoquímica}

No procedimento de imunoistoquímica, os cortes foram incubados por 1 hora em solução composta por Triton X-100 (Amresco, EUA) 0,4\%, soro normal de burro (NDS) (Chemicon, EUA) em PBS 0,1M. Na seqüência, os cortes foram incubados com solução contendo os anticorpos primários anti-CalB (Sigma, 1:1000), anti-CalR (Chemicon International Inc., Temecula, CA. 1:1000), anti-VP (Chemicon International Inc., Temecula, CA. 1:1000), anti-VIP (Chemicon International Inc., Temecula, CA. 1:1000), 
anti-NeuN-1:20000 (Millipore Corporation, 290 Concord Road,Billerica, MA01730-USA), anti-5HT-1:5000 (Protos Biotech NT-102 NY,USA). Os anticorpos primários foram diluídos em PBS 0.1 M com $0.3 \%$ Triton X-100 por 48 horas. Em seguida, foram incubados por 2 horas em anticorpos secundários biotinilados contra os animais nos quais foram produzidos os primários; séries adjacentes foram coradas com tionina para controle citoarquitetônico. Em alguns casos o anticorpo primário foi omitido para controle de marcação inespecífica.

Para a técnica de imunofluorescência, após a incubação no anticorpo primário, os cortes foram lavados em PBS 0,1M e incubados em solução contendo PBS 0,1M, Triton X100, e o anticorpo secundário fluorescente Rodamina (1:200) (Jackson Immunores. Labs, PA, USA) e FITC (1:500) (Jackson Immunores. Labs, PA, USA) por 2 horas. Em seguida foram montados em lâminas gelatinizadas, e cobertos com lâminunas utilizando-se o tampão glicerol (Sigma Chemical, St. Louis, MO, USA) como meio de montagem, estocados e protegidos da luz à $4{ }^{\circ} \mathrm{C}$.

Para cada animal, dois cortes coronais do NSQ com distância de $400 \mu \mathrm{m}$ são analisados representando as porções rostral e caudal do núcleo.

A distribuição de corpos celulares e fibras foram analizadas em microscopia de luz e fluorescência (Nikon Eclipse E1000, USA).

As imagens e desenhos relativos às terminações 5HT, TRH e NPY foram realizadas utilizando-se lâminas produzidas em experimentos anteriores de nosso laboratório cujos protocolos estão descritos em Pinato et al. (2006), Frazão et al. (2008), Pinato et al. (2009). 
4 RESULTADOS 


\subsection{Neuroquímica}

Células imunorreativas à calbindina (CalB-IR) são mais abundantes no NSQ do Cebus apella do que os CalR-IR e assim como em outras espécies, sendo que esta marcação pode ser utilizada para delimitação do núcleo (Figuras 5A-D, 12A-C e 13A-B). Os corpos de neurônios CalB-IR estão localizados em grande número em toda a extensão rostro caudal e preenchem as regiões dorsal, ventral, medial e distal do núcleo.

A distribuição de células imunorreativas à calretinina (CalR-IR) diferiu nos cortes analisados ao longo do eixo rostro-caudal do NSQ, com poucos corpos de neurônios CalRIR presentes nos cortes analisados (Figuras 6A-D; 12D-F e 13C-D). No nível rostral encontramos alguns corpos de neurônios distribuídos pelas regiões ventral, lateral, dorsal e medial do núcleo (Figura 6A,C), enquanto no nível caudal do núcleo encontramos maior densidade de neurônios distribuídos nas regiões dorsal e medial do núcleo (Figura 6B,D).

A distribuição da imunorreatividade ao VIP mostrou muitos corpos de neurônios e fibras fortemente imunorreativos ao VIP (VIP-IR) aglomerados na região ventral do NSQ no corte que representa o nível rostral (Figuras 8A,C, 9A,C, 12J e 13 G,I). Já no nível caudal, corpos de neurônios VIP-IR se concentram na região ventro-lateral e as fibras VIPIR preenchem as regiões dorsal, ventral e distal do núcleo (Figuras 8B,D, 9B,D, 12K e 13 $\mathrm{H}, \mathrm{J})$.

A imunorreatividade a NeuN mostrou no nível rostral do NSQ um aglomerado de neurônios na região central (Figuras 10A,C, 12M e 13K), e no nível caudal aparecem dois grupamentos celulares NeuN-IR, um na região ventral do núcleo e outro na região dorsal (Figuras 10B,D, 12N e 13L).

A distribuição de células imunorreativas à vasopressina (VP-IR) diferiu nos cortes analisados ao longo do eixo rostro-caudal do NSQ. Na porção rostral há maior número de corpos de neurônios e fibras imunorreativas a VP na região dorso-medial (Figura 11A,C, $12 \mathrm{P}$ e $13 \mathrm{M})$. Na porção caudal podemos observar menor densidade de corpos e fibras VP- 
IR distribuídos nas regiões dorsal, ventral, medial e distal do núcleo (Figura 11B,D, 12Q e $13 \mathrm{~N})$. 


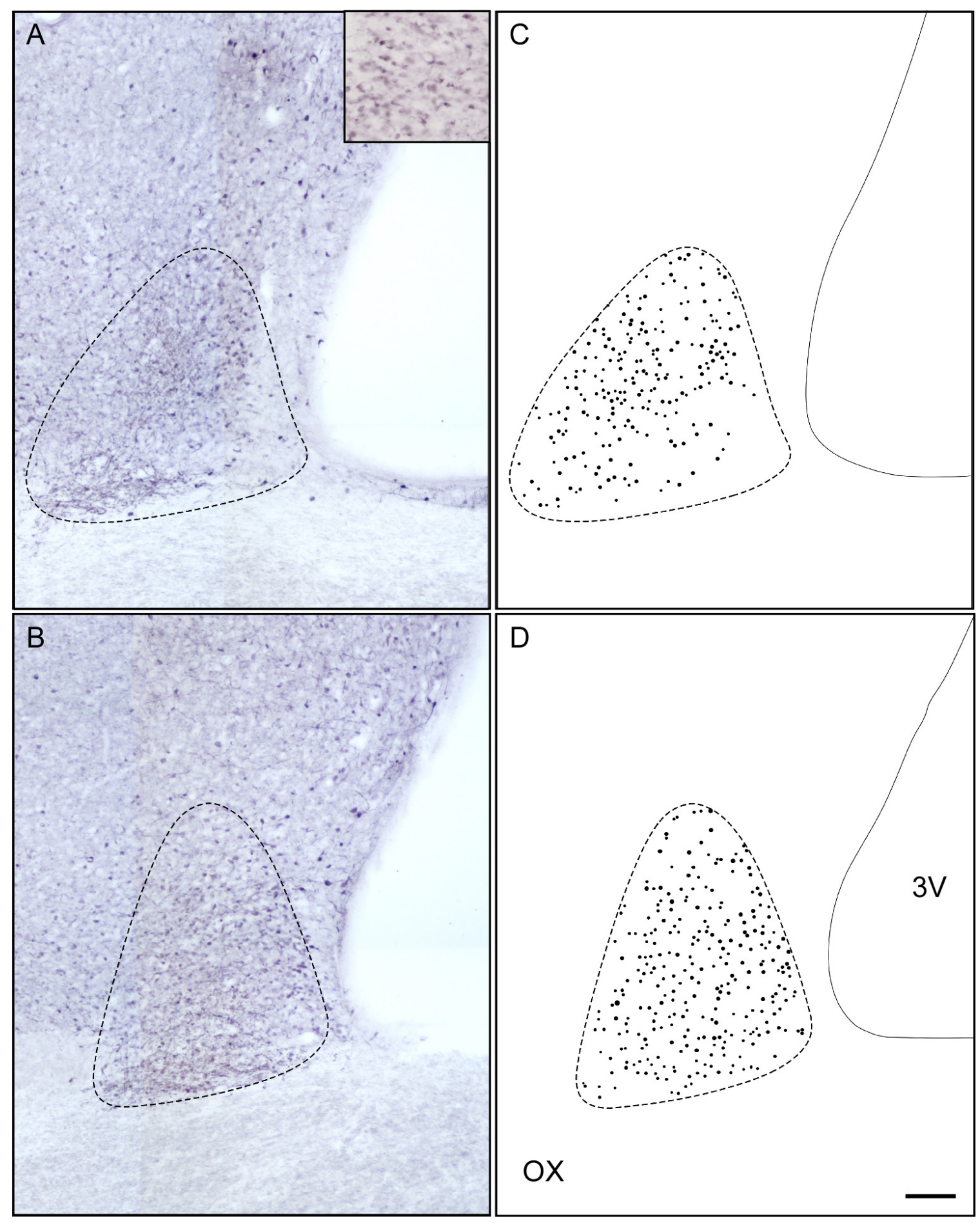

Figura 5. Em A e B, organização dos corpos de neurônios e fibras imunorreativas a calbindina (CalB-IR) no NSQ do Cebus apella em fotomicrografias de cortes coronais ao longo do eixo ântero-posterior em microscopia de campo claro e desenhos esquemáticos ilustrando a organização destes corpos de neurônios (C e D). $3 \mathrm{~V}=$ terceiro ventrículo; $\mathrm{OX}=$ quiasma óptico. Escala: $200 \mu \mathrm{m}$. 




Figura 6. Em A e B, organização dos corpos de neurônios e fibras imunorreativas a calretinina (CalR-IR) no NSQ do Cebus apella em fotomicrografias de cortes coronais ao longo do eixo ântero-posterior em microscopia de campo claro e desenhos esquemáticos ilustrando a organização destes corpos de neurônios (C e D). 3V = terceiro ventrículo; OX = quiasma óptico. Escala: $200 \mu \mathrm{m}$. 


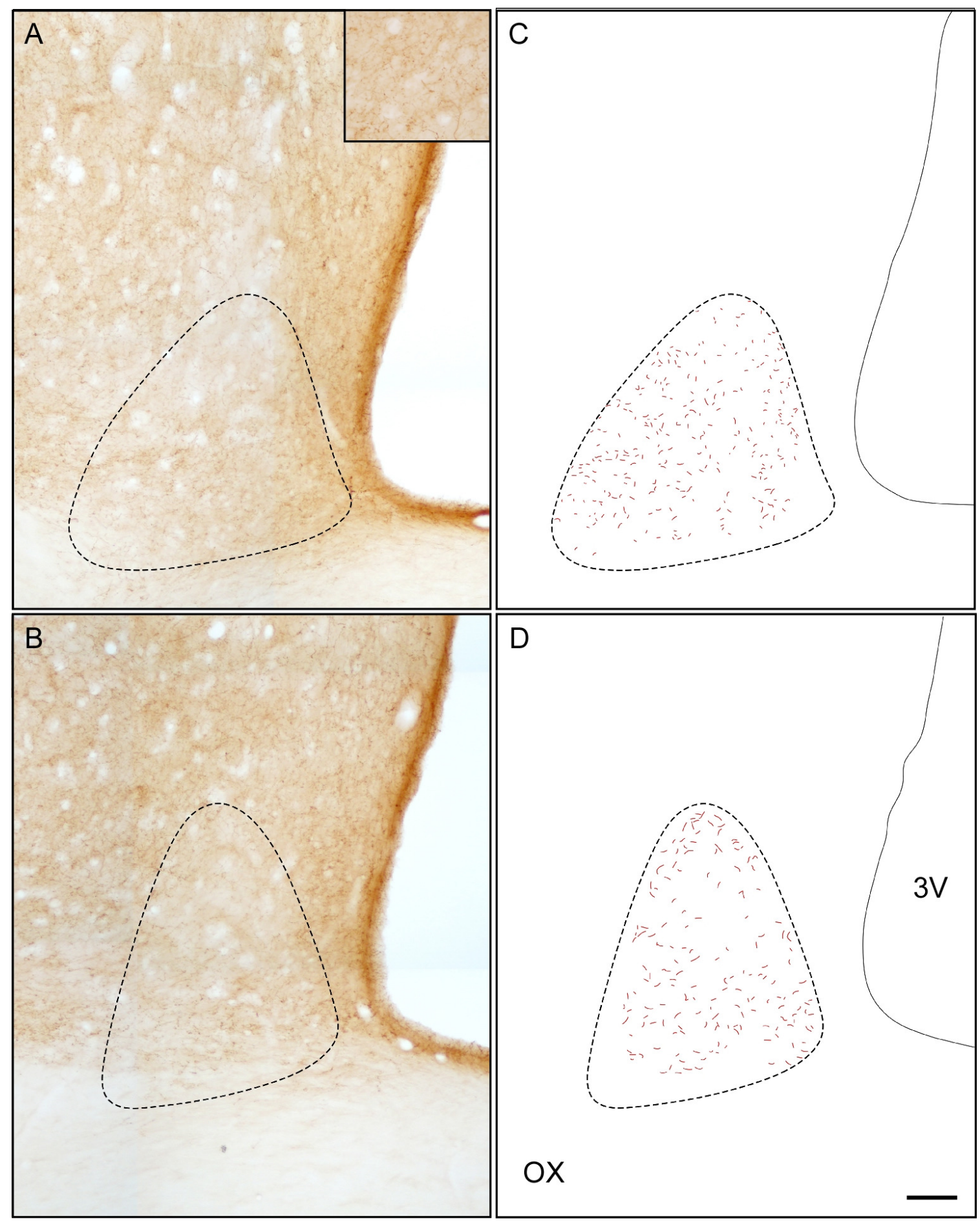

Figura 7. Em A e B, organização das fibras imunorreativas a 5H-T(5H-T-IR) no NSQ do Cebus apella em fotomicrografias de cortes coronais ao longo do eixo ântero-posterior em microscopia de campo claro e desenhos esquemáticos ilustrando a distribuição das fibras (C e D). 3V = terceiro ventrículo; OX = quiasma óptico. Escala: $200 \mu \mathrm{m}$. 


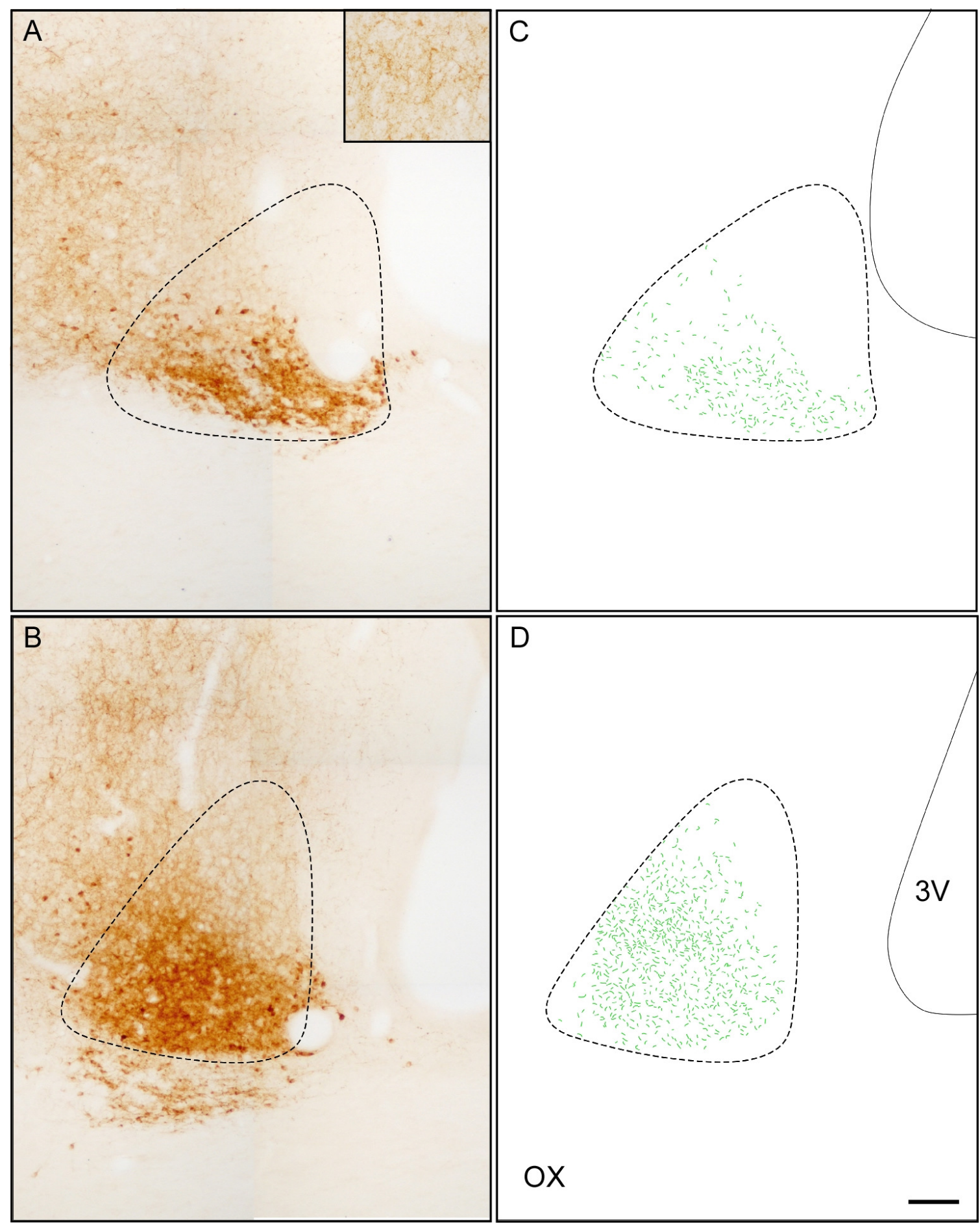

Figura 8. Em A e B, organização dos corpos de neurônios e fibras imunorreativas a VIP-IR no NSQ do Cebus apella em fotomicrografias de cortes coronais ao longo do eixo ânteroposterior em microscopia de campo claro e desenhos esquemáticos ilustrando o padrão de fibras (C e D). $3 \mathrm{~V}=$ terceiro ventrículo; OX = quiasma óptico. Escala: $200 \mu \mathrm{m}$. 


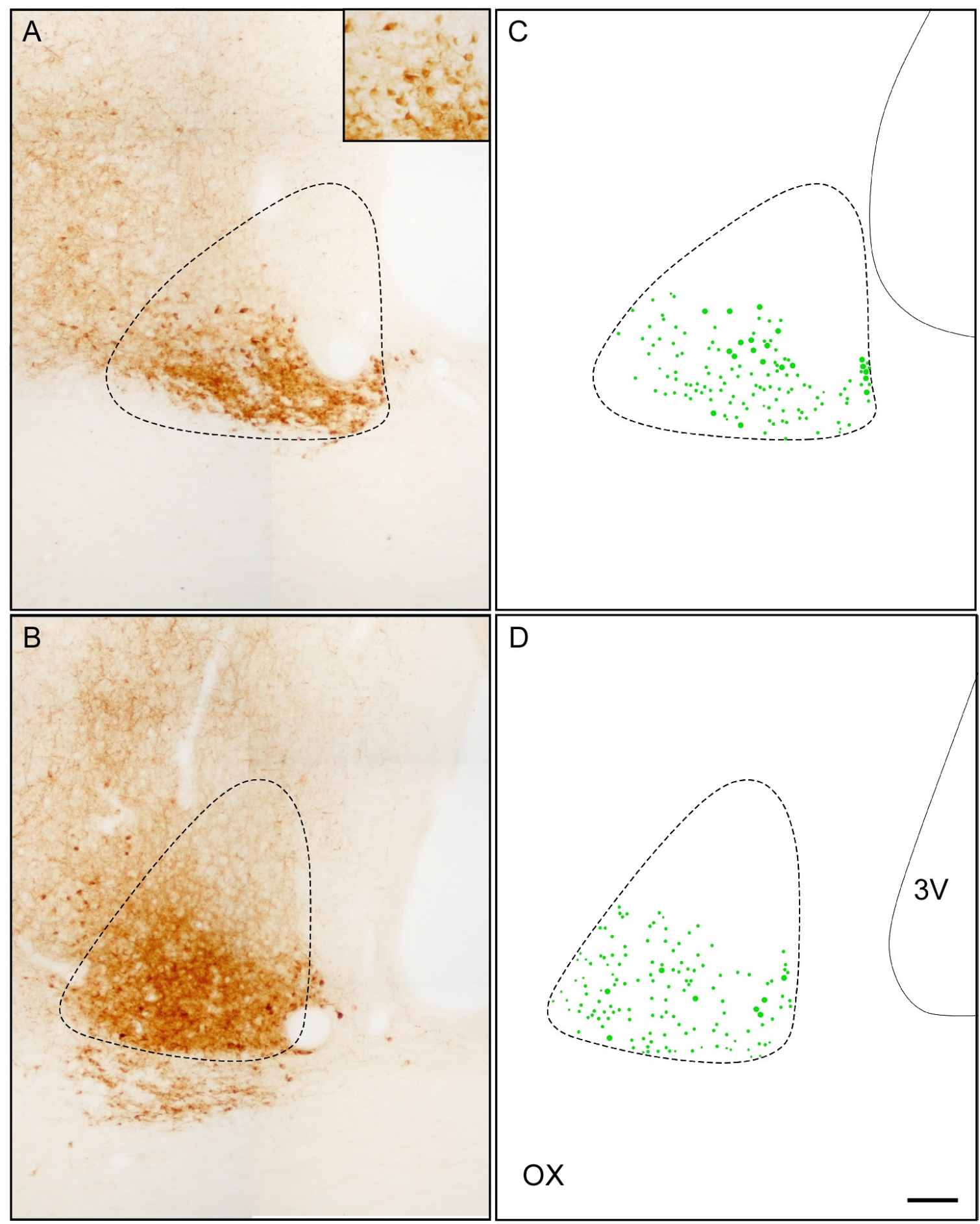

Figura 9. Em A e B, organização dos corpos de neurônios e fibras imunorreativas a VIP-IR no NSQ do Cebus apella em fotomicrografias de cortes coronais ao longo do eixo ânteroposterior em microscopia de campo claro e desenhos esquemáticos ilustrando a organização destes corpos de neurônios (C e D). 3V = terceiro ventrículo; $O X=$ quiasma óptico. Escala: $200 \mu \mathrm{m}$. 


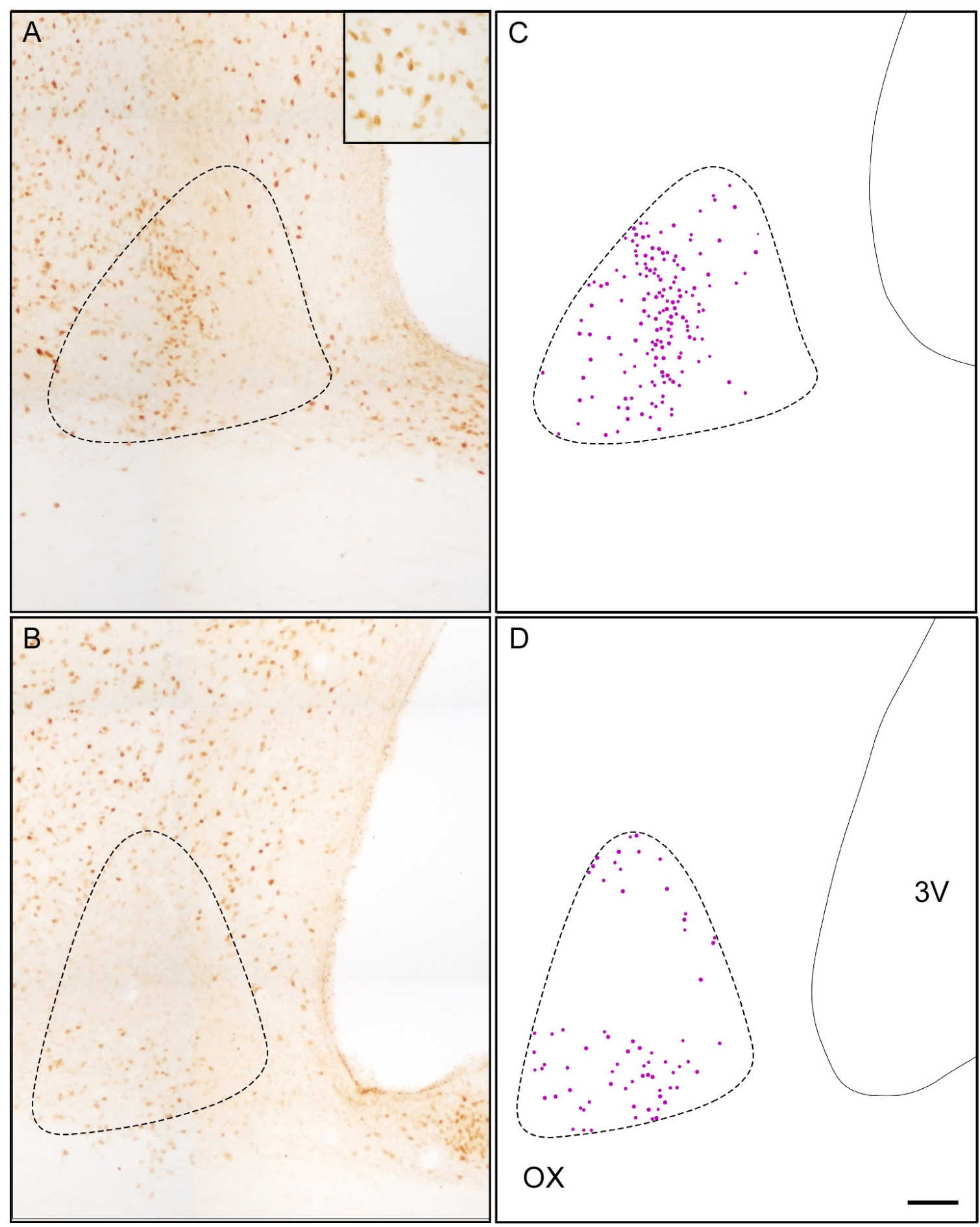

Figura 10. Em A e B, organização dos corpos de neurônios e fibras imunorreativas NeuN (NeunIR) no NSQ do Cebus apella em fotomicrografias de cortes coronais ao longo do eixo ântero-posterior em microscopia de campo claro e desenhos esquemáticos ilustrando a distribuição da Neun-IR (C e D). 3V = terceiro ventrículo; OX = quiasma óptico. Escala: $200 \mu \mathrm{m}$. 


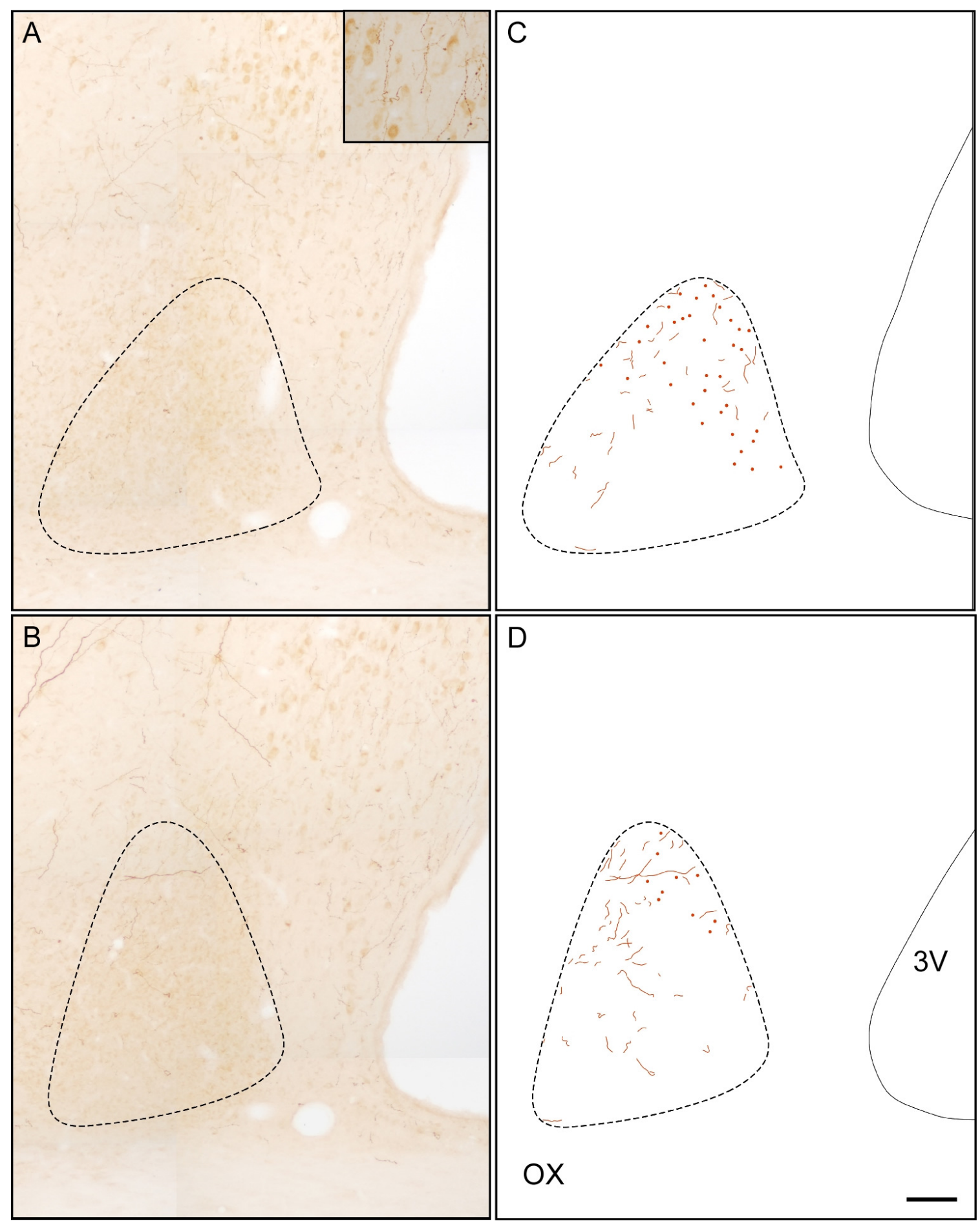

Figura 11. Em A e B, organização dos corpos de neurônios e fibras imunorreativas a vasopressina (VP-IR) no NSQ do Cebus apella em fotomicrografias de cortes coronais ao longo do eixo ântero-posterior em microscopia de campo claro e desenhos esquemáticos ilustrando a organização dos corpos de neurônios e fibras VP-IR (C e D). 3V = terceiro ventrículo; OX = quiasma óptico. Escala: $200 \mu \mathrm{m}$. 


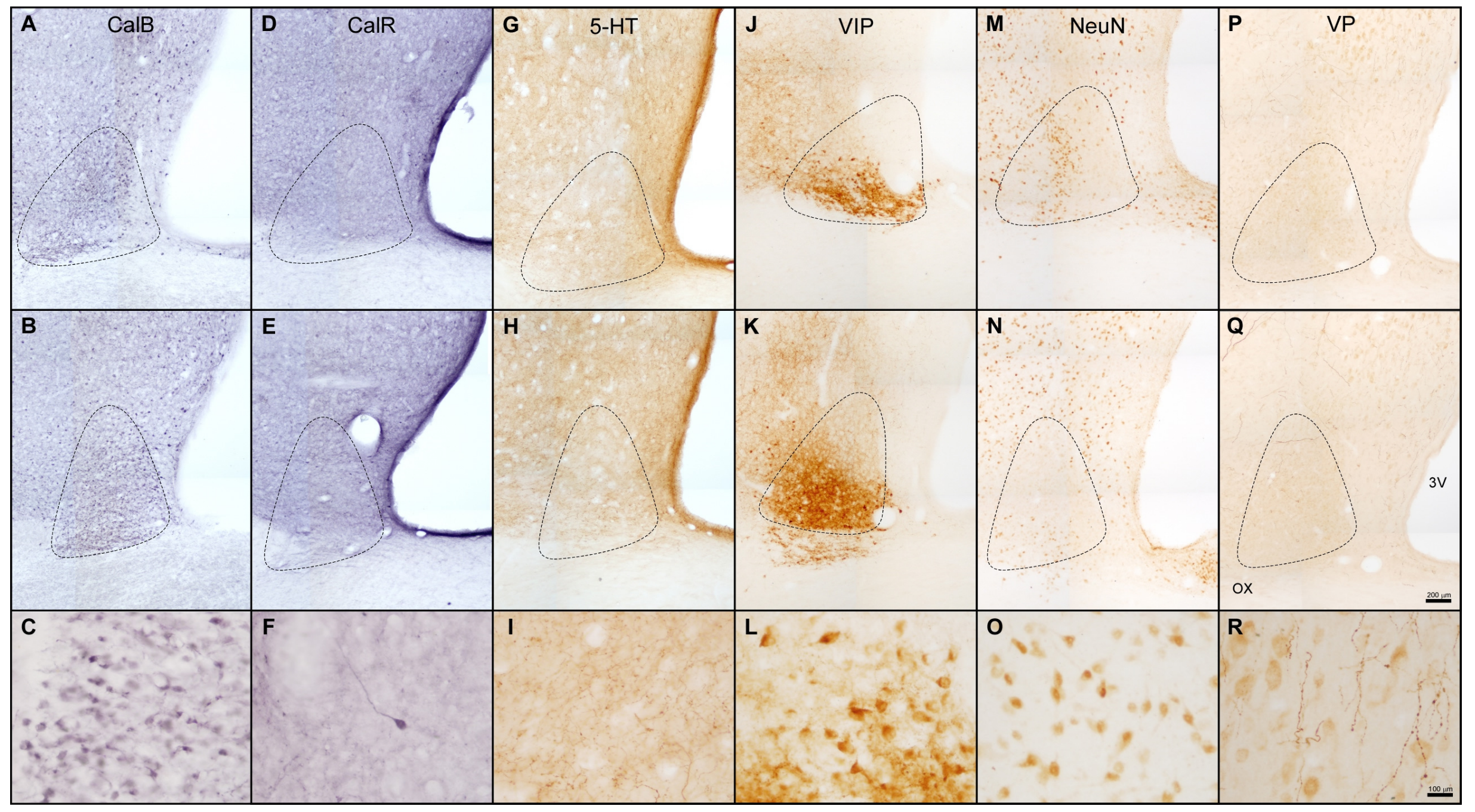

Figura 12. Fotomicrografias de cortes coronais ao longo do eixo ântero-posterior em microscopia de campo claro no NSQ do Cebus apella. Em A, B, C organização dos corpos de neurônios e fibras imunorreativas a calbindina (CalB-IR); Em D, E, F organização dos corpos de neurônios e fibras imunorreativas a calretinina (CalR-IR); Em G, H, I organização das fibras imunorreativas a 5H-T (5H-T-IR); Em J, K, L organização dos corpos de neurônios e fibras imunorreativas a VIP (VIP-IR); Em M, N, O organização dos corpos de neurônios e fibras imunorreativas NeuN (Neun-IR); Em P, $\mathrm{Q}, \mathrm{R}$ organização dos corpos de neurônios e fibras imunorreativas a vasopressina (VP-IR). 3V = terceiro ventrículo; OX = quiasma óptico. 


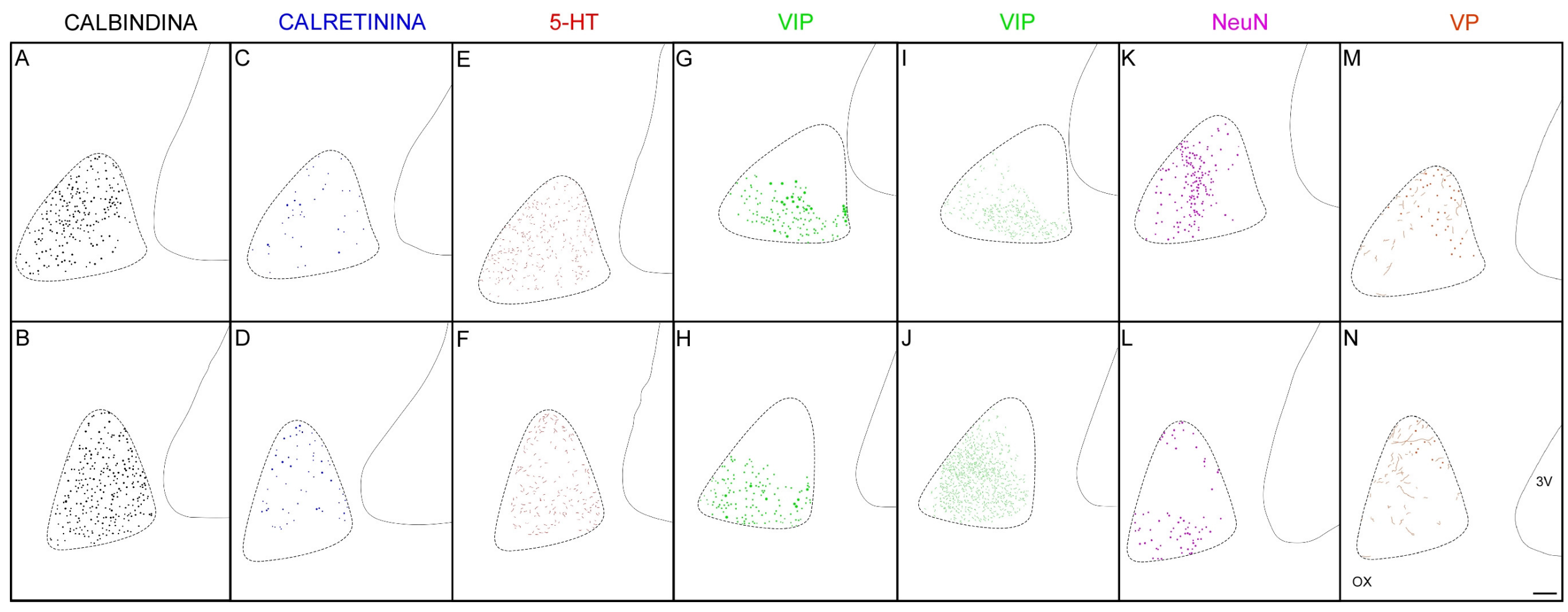

Figura 13. Desenhos esquemáticos de cortes coronais ao longo do eixo ântero-posterior no NSQ do Cebus apella. Em A, B organização dos corpos de neurônios e fibras imunorreativas a calbindina (CalB-IR); Em C,D organização dos corpos de neurônios e fibras imunorreativas a calretinina (CalR-IR); Em E,F organização das fibras imunorreativas a 5H-T (5H-T-IR); Em G-J organização dos corpos de neurônios e fibras imunorreativas a VIP (VIP-IR); Em K,L organização dos corpos de neurônios e fibras imunorreativas NeuN (Neun-IR); Em M,N organização dos corpos de neurônios e fibras imunorreativas a vasopressina (VP-IR). $3 \mathrm{~V}=$ terceiro ventrículo; $\mathrm{OX}=$ quiasma óptico. Escala: $200 \mu \mathrm{m}$. 


\subsection{Sobreposição dos diferentes grupos de células imunorreativas com as principais terminações aferentes}

Ao observarmos os padrões de distribuição de células CalB-IR e CalR-IR (Figuras 12A-F) e compararmos com o padrão de terminais CTB-IR (Figura 14E-H) podemos inferir que há células marcadas com estas duas proteínas ligantes de cálcio na região retinorecipiente do núcleo. Ainda no nível rostral onde encontramos a maior concentração de fibras CTB-IR (Figura 14E) e de corpos marcados com VIP (Figura 12J) não há sobreposição de terminais retinianos com células ou fibras imunorreativas a VP (Figura 14I). O padrão se altera quando analisamos o corte que representa ao nível caudal do núcleo onde encontramos sobreposição de fibras CTB-IR e fibras VP-IR na região central e dorsal do núcleo (Figura 14J,K).

Quando analisamos a possivel sobreposição de células NeuN-IR e VP-IR verificamos no nível rostral sobreposição de corpos celulares na região dorsal do núcleo (Figura 15E). Já no nível caudal há sobreposição destas duas marcações nas regiões dorsal e vetro-lateral do núcleo (Figura 15H,I) 



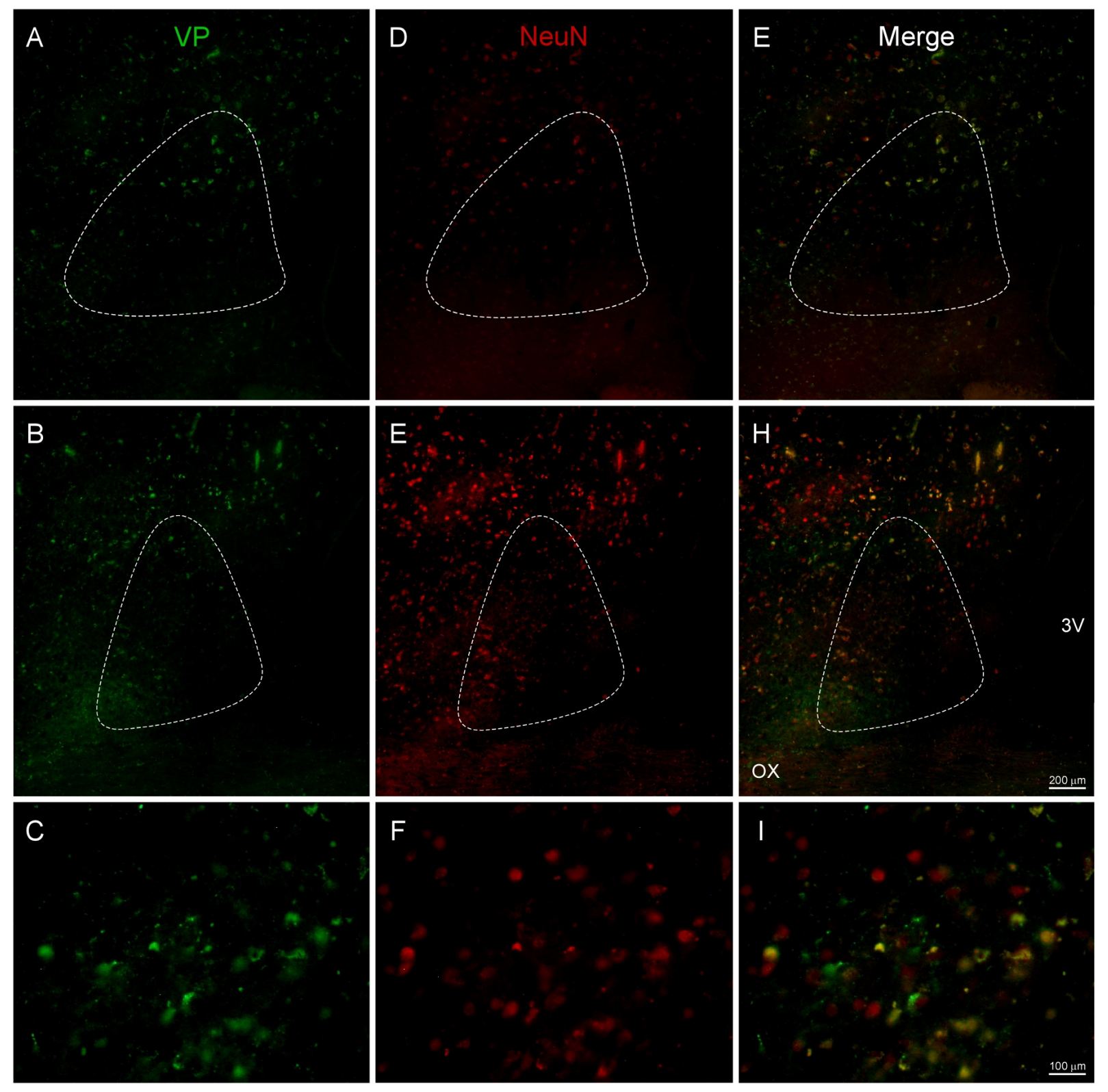

Figura 15. Fotomicrografias em fluorescência de cortes coronais ao longo do eixo ântero- posterior do NSQ do Cebus apella. Em A, B, C organização dos corpos de neurônios e fibras imunorreativas a vasopressina (VP-IR); Em D, E, F organização dos corpos de neurônios e fibras imunorreativas NeuN (Neun-IR); Em G, H, I co-localização dos corpos de neurônios imunorreativas a vasopressina e NeuN . 3V = terceiro ventrículo; $\mathrm{OX}=$ quiasma óptico. 


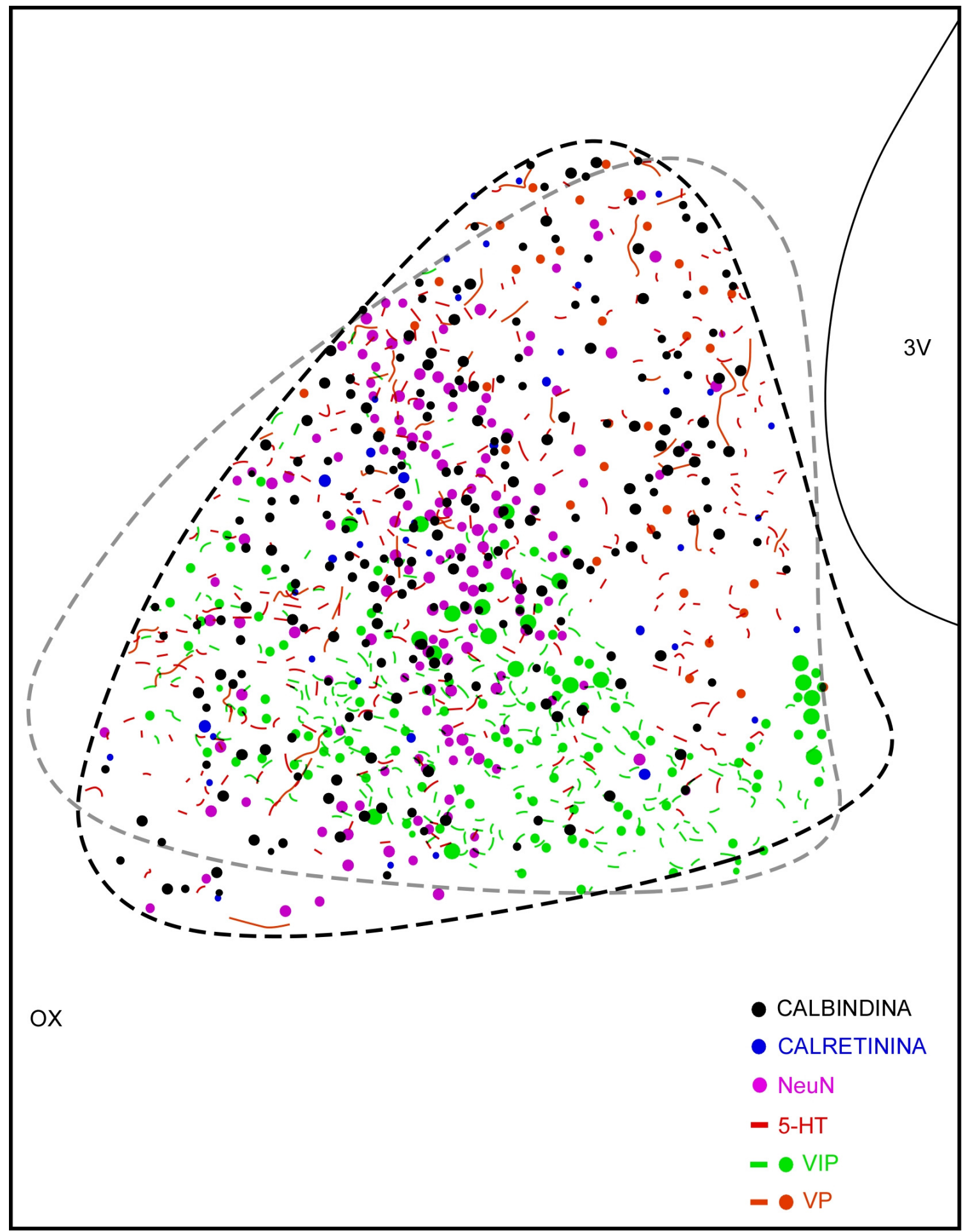

Figura 16. Desenho esquemático do NSQ de Cebus Apella demonstrando a sobreposição dos diferentes grupos de células imunorreativas: calbindina, calretinina, Neun, 5-HT, VIP e VP. $3 \mathrm{~V}=$ terceiro ventrículo; $\mathrm{OX}=$ quiasma óptico. 


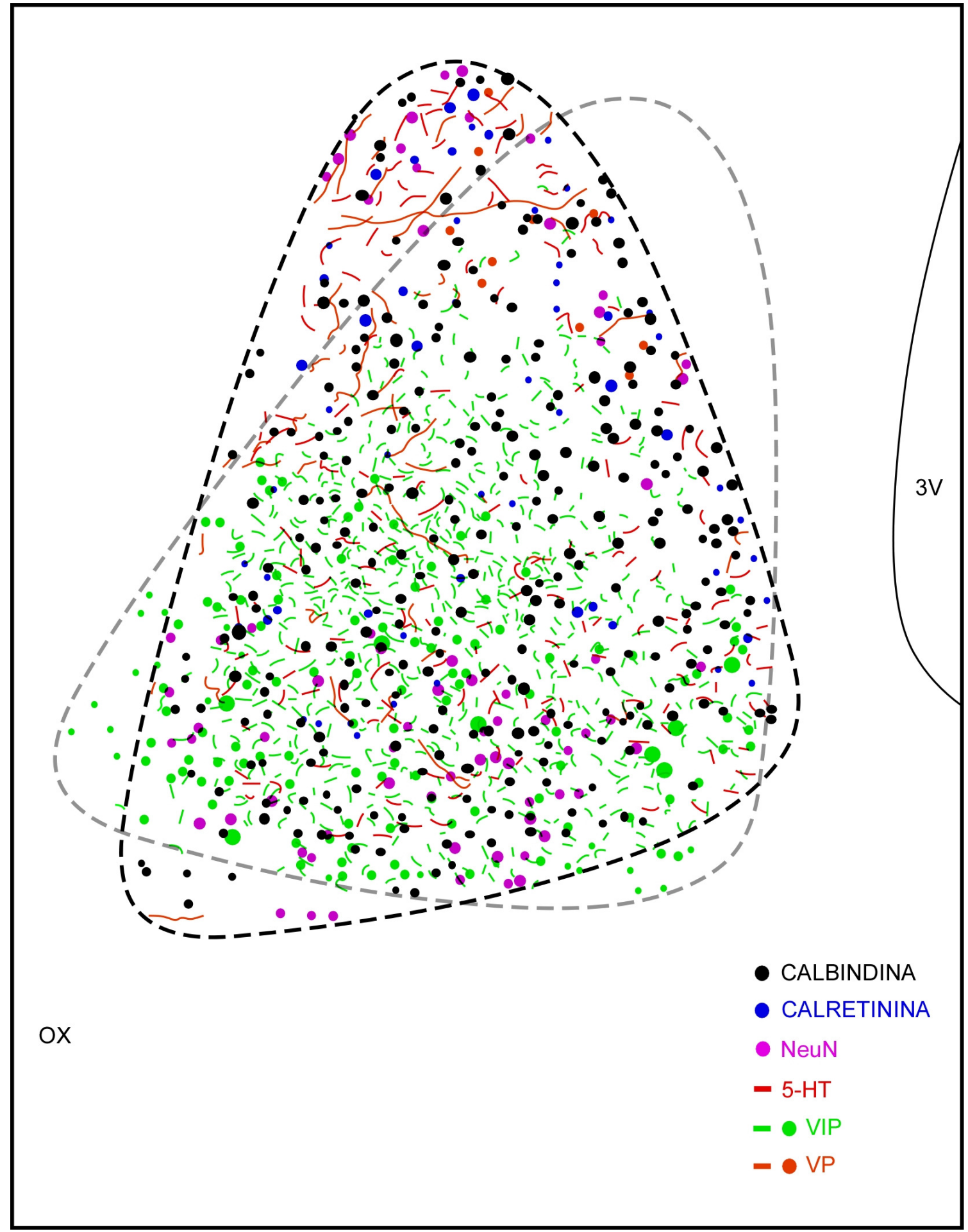

Figura 17. Desenho esquemático do NSQ de Cebus Apella demonstrando a sobreposição dos diferentes grupos de células imunorreativas: calbindina, calretinina, Neun, 5-HT, VIP e VP. 3V = terceiro ventrículo; $\mathrm{OX}=$ quiasma óptico. 
O NSQ pode ser facilmente distinguido do hipotálamo adjacente pela presença de uma variedade de indicadores neurais. A marcante coloração de Nissl nos neurônios do NSQ é muito utilizada para identificar neurônios por todo o NSQ (Moore et al., 1991; Abrahamson e Moore, 2001). O presente estudo complementa os resultados de estudos anteriores demonstrando a distribuição de diferentes substâncias neuroativas no NSQ do primata Cebus apella e demonstra que as distribuições destes grupos de células diferem das demais espécies descritas na literatura (Morin e Allen, 2006).

Fica claro que, algumas destas células se sobrepõem e ao menos alguns neurônios de todos os tipos investigados estão presentes em regiões que recebem aferências retinianas, serotonérgicas ou terminais contendo NPY (Pinato et al., 2007; Pinato et al., 2009).

As distribuições dos terminais aferentes e dos grupos celulares analisados enfatizam a complexidade organizacional do NSQ no Cebus apella e apontam diferenças consideráveis quando comparada com outras espécies.

\subsection{Organização dos grupos celulares no NSQ}

Os neurônios CalB-IR são encontrados em grande quantidade no NSQ do Cebus apella, por toda a extensão do núcleo. Em camundongos e ratos os neurônios CalB-IR estão distribuídos de forma mais ou menos complementar aos neurônios CalR-IR com grande densidade de células nas regiões dorsomedial e dorsolateral e ausência na região central (Morin et al., 2006). No NSQ de hamsters, por exemplo, CalB e substância P estão concentradas em uma região central da porção caudal do núcleo, que contém relativamente poucas células com VIP ou VP (Morin et al., 1992; Silver et al., 1996).

A distribuição das células CalB varia um pouco através das espécies, e não está no NSQ de todas as espécies. É visto em todo o NSQ de sagüis (Costa e Britto, 1997) e Cryptomys (Negroni et al., 2003), no NSQ dos seres humanos (Mai et al., 1991) e nas porções periféricas do núcleo em ratos (Celio, 1990). 
O presente estudo mostra uma quantidade menor de células CalR-IR do que a relatada para outras espécies, com distribuição variável ao longo do eixo rostro-caudal. Estudos em roedores mostram uma abundância de células CalR-IR no NSQ, sendo a parte ventral do núcleo a região de maior densidade destas células (Morin et al., 2006). Outros estudos demonstraram localização mais restrita (Abrahanson e Moore, 2001) e ainda distribuição similar a das células VP-IR (Silver et al., 1999). A típica localização ventral da maior densidade de células encontrada em roedores não foi encontrada neste estudo, que mostra corpos de neurônios CalR-IR isolados nas regiões dorsal, ventral e medial no NSQ. Em ratos neurônios CalR-IR são uma das maiores populações no NSQ, representam 14\% do núcleo, esses neurônios estão localizados na porção dorsal e lateral do NSQ, mas se estendem além das fronteiras do NSQ (Moore et al., 2002).

Quanto a imunorreatividade ao VIP, o segundo peptídeo a ser identificado no NSQ (Samson et al., 1979), assim como no camundongo, no Cebus apella neurônios contendo VIP estão presentes, no seu nível mais rostral, ao longo da margem ventral do NSQ, sendo que, alguns estudos descrevem neurônios estendendo-se ao longo da margem medial próximo ao terceiro ventrículo (Silver et al., 1999; Morin et al., 2006) e outros descrevem apenas localização ventral dos neurônios VIP-IR (Abrahanson e Moore, 2001). Em hamsters, a expressão de VIP é ocasionalmente colocalizada com a de CalB. Em ratos, as células contendo VIP podem ser divididos em um grupo medial e um grupo lateral (Kawamoto et al., 2003). Conhecidamente como as células que recebem a informação fótica que chega pelo TRH, elas projetam principalmente para as estruturas locais em torno do NSQ, incluindo a porção dorsomedial (Leak e Moore, 2001). Assim, neurônios VIP-IR participam em ligações locais dentro da região ventral e com os neurônios VP-IR na região dorsal (Ibata et al., 1993). Esta característica parece se manter no NSQ do Cebus apella já que observamos grande densidade de fibras VIP-IR espalhando-se na região dorsal, principalmente no nível caudal do núcleo. Em roedores aferências da retina, as fibras de NPY do IGL e fibras 5-HT dos neurônios, fazem contatos sinápticos com as células VIP (Hisano et al., 1988; Ibata et al., 1989). Quanto aos terminais retinianos, verificamos o mesmo padrão de sobreposição com as células VIP-IR no Cebus apella. Estes dados corroboram a hipótese de que os neurônios VIP estão envolvidos na sincronização dos 
ritmos circadianos. Porém, quanto as aferencias contendo NPY e 5-HT Isto parece não ser verdadeiro em algumas species de primatas como no marmoset (Cavalcante et al., 2002) e no Cebus apella (Pinato et al., 2007; Pinato et al., 2009) onde parece não haver sobreposição destes terminais com células VIP-IR.

Ao contrário da VP, foi constatado que o conteúdo VIP no NSQ do rato não mostra ritmo circadiano em livre-curso, mas em condições de claro-escuro, diminui ao longo da fase de luz, recuperando-se gradualmente durante a fase escura (Shinohara et al., 1993).

O principal neuropeptídeo expresso na subdivisão dorsomedial do NSQ, conservado em todas as espécies de mamíferos, inclusive Cebus apella, como observado neste trabalho, é a vasopressina. Embora esta localização dorsomedial seja frequentemente considerada uma característica padrão do NSQ de mamíferos (Moore et al., 2002), como no golden hamster (Card e Moore, 1984), rato (Van den Pol e Tsujimoto, 1985; Buijs et al.,1995; Moore et al., 2002; Morin et al., 2006), camundongo (Cassone et al., 1988; Abrahamson e Moore, 2001; Morin et al., 2006), esquilo (Reuss et al., 1989), rato da grama (Smale and Boverhof, 1999) e degu (Goel et al., 1999), estas células podem estar ausentes ou ainda apresentarem diferentes distribuições em algumas espécies. Atualmente, em apenas duas espécies, a musaranho-almiscarado (Tokunaga et al., 1992) e na marta (Martinet et al., 1995), foram identificados ausência de células VP-IR no NSQ.

Sob condições de claro-escuro, os níveis de VP revelam um pico de luz na fase inicial e uma queda na fase escura, um padrão que se mantém no escuro constante, ou luz constante, caracterizando um ritmo circadiano no NSQ de ratos (Tominaga et al., 1992). Além disso, há evidências de que as células VP estão envolvidos na transmissão de informações de tempo sobre a atividade do NSQ para outras partes do cérebro (Bult et al., 1993; Buijs et al., 1995).

A pequena expressão da proteína neuronal específica nuclear (NeuN) no NSQ do Cebus apella corrobora com o resultado de ratos adultos (Geoghegan e Carter, 2008). NeuN, (Neuronal Nuclei), é usado extensivamente para identificar as células nervosas no 
sistema nervoso de vertebrados adultos de uma variedade de espécies, incluindo roedores e seres humanos. Aparentemente muitas das células do NSQ do Cebus apella são neurônios NeuN negativos, isto não é uma caracteristica unica deste núcleo, em roedores outras regiões como células de Purkinje do cerebelo, Cajal-Retzius neurônios da primeira camada do córtex cerebral, os neurônios do núcleo olivar inferior, células mitral do bulbo olfatório, fotorreceptores da retina são neurônios NeuN-negative, (Kumar e Buckmaster, 2007; Mullen RJ et al., 1992; Sarnat et al., 1998; Weyer e Schilling, 2003). No gerbil (Meriones unguiculatus) neurônios especificos da substencia negra pars reticulata $(\mathrm{SNr})$, também são desprovidos de imunorreatividade a NeuN, contrariamente ao que acontece em ratos (Kumar e Buckmaster, 2007) .

O significado desta falta de expressão desta proteina em neurônios de regiões específicas, assim como o porque das diferenças interespecificas em determinadas regiões ainda não foi esclarecida. Nosso resultado de dupla marcação NeuN e VP mostra que parte dos neurônios NeuN-IR colocalizam com a marcação VP-IR, mas a completa definição das carcteristicas neuroquimicas das celulas NeuN-negativas do SCN deve ser realizada futuramente.

\subsection{Colocalização dos corpos neuronais com as principais terminações aferentes.}

Na espécie de primata analisada, assim como no camundongo e no hamster, o TRH ocupa a maior parte do NSQ (Johnson et al., 1988; Silver et al., 1999; Muscat et al., 2003; Hattar et al., 2006).

No Cebus há menos, terminais retinianos na região dorso medial ocupada pelos neurônios VP-IR sem sobreposição dos terminais do TRH com células VP-IR, já que células VP-IR expressam a proteína Fos (marcador de atividade neuronal) quando estimuladas por luz (Castel et al., 1997), este resultado sugere relação funcional indireta entre projeções retinianas e atividade de células VP-IR, provavelmente a informação luminosa deva alcançar diretamente as células VIP-IR que se projetariam para as VP-IR. 
Entretanto para sabermos se os terminais retinianos que se sobrepõem a corpos neuronais VIP-IR fazem contato com esses neurônios será necessário, em futuro estudo, utilizar análise por microscopia eletrônica.

Os terminais do TRH do Cebus apella também colocalizam-se com a maioria das células CalB-IR e CalR-IR e quase todos os neurônios CalB-IR recebem terminais serotoninérgicos (Kriegsfeld et al., 2004;. LeSauter et al., 2002). Em contraste com o rato, onde o TRH termina em uma forma mais concentrada colocalizando-se com células CalRIR (Johnson et al., 1988; Moore et al., 2002; Morin et al., 2006).

As fibras imunorreativas para NPY parecem estar presente no NSQ de muitos mamíferos que foram examinados (Card e Moore, 1984; Smith et al., 1985; Ueda et al., 1986;. Cassone et al., 1988; Reuss et al., 1989; Bons et al., 1990; Smale et al., 1991; Moore, 1993). Nossos resultados mostram que no Cebus apella, espécie de primata de hábitos diurnos, o NSQ apresenta fibras NPY-IR distribuídas esparsamente pelo núcleo, com pouca sobreposição aos grupamentos celulares intrínsicos ao NSQ.

A aferência serotonérgica no NSQ do primata Cebus apella (Pinato et al., 2007) apresenta uma zona central de terminais relativamente esparsos ou ausentes e uma periferia que varia entre moderadamente e intensamente ocupada por terminais imunoreativos à 5HT, sobrepondo-se principalmente a células CalB-IR e poucas células VIP-IR, onde em roedores há grande sobreposição. Este dado juntamente com o fato de terminais 5-HT-IR sobreporem poucos terminais retinianos, reforça a idéia que a importância da 5-HT e do NPY na modulação dos estímulos fóticos que sincronizam os ritmos gerados pelo NSQ estaria diminuída nesta espécie.

Tal como acontece com a anatomia do NSQ, as funções de vários indicadores deste núcleo parece ser a mesma em espécies com diferentes padrões de atividade. Este é o caso dos ritmos de atividade metabólica, da expressão de genes que são fundamentais para oscilação molecular do núcleo e a expressão de genes que codificam proteínas e peptídeos (Smale et al., 2008). A significância das diferenças na organização do NSQ das espécies é 
desconhecida, porém, aquelas que foram identificados não têm sido associados com o fato de um animal ser noturno ou diurno. 
O presente estudo de análise dos tipos celulares presentes e sua distribuição no NSQ do primata Cebus apella está em concordância com estudos recentes que têm discordado de classificação simplificada proposta anteriormente que sugere duas, três ou quatro divisões dentro do NSQ, baseados na distribuição dos tipos celulares e dos terminais presentes no núcleo de roedores e relacionam a localização destes e suas relações com as funções do NSQ.

Nossos resultados demonstram uma complexidade organizacional que vai além das divisões classicamente propostas em roedores e ainda evidencia importantes diferenças nas relações entre terminais e grupos celulares nesta espécie. Se estas diferenças na distribuição de células peptidérgicas e terminais aferentes refletem ou não diferenças funcionais no NSQ essa é uma questão a ser explorada.

Estes resultados demonstram que a extrapolação dos conhecimentos adquiridos em roedores para primatas e humanos podem além de confundir o mapeamento de tipos celulares, inferirem falsas funções a cada grupamento neuronal.

A importância de se continuar investigando estas características se torna ainda maior levando-se em conta que, como tem sido relatado na literatura, pode haver mudanças dinâmicas nessa aparente organização.

Para que haja o total entendimento da função do vários setores do NSQ novos estudos devem ser feitos, principalmente em primatas, para que possamos entender os aspectos evolutivos do sistema de temporização circadiana e suas variações em animais diurnos. Este estudo revela a importância da investigação e o conhecimento de cada vez mais detalhes da distribuição dos vários tipos celulares, suas relações sinápticas e a anatomia das projeções que chegam de áreas que influenciam a função do relógio circadiano, principalmente retina, folheto intergenigulado e rafe. 
REFERÊNCIAS 


\section{REFERÊNCIAS*}

Abe H, Honma S, Shinohara K, Honma K Substance $\mathrm{P}$ receptor regulates the photic induction of Fos-like protein in the suprachiasmatic nucleus of Syrian hamsters. Brain Res. 1996;708(1-2):135-42.

Abrahamson EE, Moore RY. Suprachiasmatic Nucleus in the mouse: Pretinal Innervationm, Intrinsic Organization and Efferent Projections. Brain Res. 2001; 916:17291.

Albrecht U, Sun ZS, Eichele G, Lee CC. A differential response of two putative mammalian circadian regulators, mper1 and mper2, to light. Cell. 1997;91(7):1055-64.

Albus H, Vansteensel MJ, Michel S, Block GD, Meijer JH. A GABAergic mechanism is necessary for coupling dissociable ventral and dorsal regional oscillators within the circadian clock. Curr Biol. 2005;15(10):886-93.

Antonopoulos J, Papadopoulos GC, Karamanlidis AN, Parnavelas JG, Dinopoulos A, Michaloudi H. VIP- and CCK-like-immunoreactive neurons in the hedgehog (Erinaceus europaeus) and sheep (Ovis aries) brain. J Comp Neurol. 1987; 263(2):290-307.

Aschoff J. Circadian rhythms in man. Science. 1965;148:1427-32.

Berson DM, Dunn FA, Takao M. Phototransduction by retinal ganglion cells that set the circadian clock. Science. 2002; 295(5557):1070-3.

Bicca-Marques JC, Silva VM, Gomes DF. Ordem Primates. In: Reis NR, Peracchi AL, Pedro WA, Lima IP. Mamíferos do Brasil. Londrina, Paraná: Universidade Estadual de Londrina; 2006.

Buijs RM, Wortel J, Hou YX. Colocalization of gamma-aminobutyric acid with vasopressin, vasoactive intestinal peptide, and somatostatin in the rat suprachiasmatic nucleus. J Comp Neurol. 1995;358(3):343-52.

\footnotetext{
* De acordo com: International Committee of Medical Journal Editors. Uniform requirements for manuscripts submitted to Biomedical Journal: sample references. Available from: http://www.icmje.org [2007 May 22].
} 
Bult A, Hiestand L, Van der Zee EA, Lynch CB. Circadian rhythms differ between selected mouse lines: a model to study the role of vasopressin neurons in the suprachiasmatic nuclei. Brain Res Bull. 1993;32(6):623-7.

Carthy JD, Howse PE. Comportamento Animal. São Paulo: EPU: Ed. da Universidade de São Paulo; 1980. v. 14. p. 79.

Cassone VM, Speh JC, Card JP, Moore RY. Comparative anatomy of the mammalian hypothalamic suprachiasmatic nucleus. J Biol Rhythms. Spring. 1988;3(1):71-91.

Cavalcante JS. Projeções retinianas e distribuição de proteínas ligantes de cálcio nas áreas retino-recipientes do hipotálamo do sagüi (Callithrix jacchus). [dissertação (Mestrado em Fisiologia)]. São Paulo: Instituto de Ciências Biomédicas da Universidade de São Paulo; 2000.

Cavalcante JS, Alves AS, Costa MSMO, Britto LRG. Differential distribution of afferents containing serotonin and neuropeptide $\mathrm{Y}$ within the marmoset suprachiasmatic nucleus. Brain Research. 2002;927:200-3

Celio MR. Calbindin D-28k and parvalbumin in the rat nervous system. Neuroscience. 1990; 35:375-475.

Chevassus-Au-Louis, $\mathrm{N}$ and Cooper HM. Is there a geniculohypothalamic tract in primates? A comparative immunohistochemical study in the circadian system of strepsirhine and haplorhine species. Brain Res 1998;805:213-19.

Costa LF, Moreira V, Alones J, Lu UR, Santee JS, Cavalcante PRA, Moraes LRG, Britto M, Menaker. Characterization of the circadian system in a brazilian species of monkey (Callithrix jacchus): immunohistochemical analysis and retinal projections, Biol. Rhythm Res. 1998;29:510-20.

Costa MS, Britto LR. Calbindin immunoreactivity delineates the circadian visual centers of the brain of the common marmoset (Callithrix jacchus). Brain Res Bull. 1997;43:369-73.

Costa MS, Santee UR, Cavalcante JS, Moraes PR, Santos NP, Britto LR. Retinohypothalamic projections in the common marmoset (Callithrix jacchus): A study using cholera toxin subunit B. J Comp Neurol. 1999;415:393-403. 
Dunlap JC, Loros JJ, DeCoursey PJ. Chronobiology Biological timekeeping. Sunderland, MA, USA: Sinauer Associates, Inc. publishers; 2004. 405 p.

Dunlap JC. Molecular bases for circadian clocks. Cell. 1999;96(2):271-90. Review.

Ferre MS, Valenzuela JG, Farfan CT. Circadian Clocks During Embryonic and Fetal Development. Birth Defects Research (Part C) 2007;81:204-14.

Fite KV, Janusonis S, foote W, Bengston L. Retinial afferents to the dorsal rephe nucleus in rats and Mongolian gerbils. J Comp Neurol.1999;414(4);469-84.

Frazão R, Pinato L, da Silva AV, Britto LR, Oliveira JA, Nogueira MI. Evidence of reciprocal connections between the dorsal raphe nucleus and the retina in the monkey Cebus apella. Neurosci Lett. 2008;430(2):119-23.

$\mathrm{Fu}$ L, Lee CC. The circadian clock: pacemaker and tumor suppressor. Nat Rev Cancer, 2003;3:350-61.

Geoghegan D, Carter DA. A novel site of adult doublecortin expression: neuropeptide neurons within the suprachiasmatic nucleus circadian clock. BMC Neuroscience. 2008;4:92.

Goel N, Lee TM, Smale L. Suprachiasmatic nucleus and intergeniculate leaflet in the diurnal rodent Octodon degus: retinal projections and immunocytochemical characterization. Neuroscience. 1999;92:1491-1509.

Green DJ, Gillete R. Circadian rhythms of firing rate recorded from single cells in the rat suprachiasmatic brain slice. Brain Res. 1882;245:198-200.

Halberg F. Chronobiology. Annual Review of Physiology. 1969;31:675-725.

Hamada T, Antle MC, Silver R. Temporal and spatial expression patterns of canonical clock genes and clock-controlled genes in the suprachiasmatic nucleus. Eur J Neurosci. 2004; 19:1741-48. 
Hannibal J, Fahrenkrug J. Immunoreactive substance $P$ is not part of the retinohypothalamic tract in the rat. Cell Tissue Res. 2002; 309(2):293-99.

Hendrickson AE, Wagoner N, Cowan WM. An autoradiographic and electron microscopic study of retinohypothalamic connections. Z Zellforsch Mikrosk Anat. 1972;135:1-26.364.

Herichová I, Mravec B, Stebelová K, Krizanová O, Jurkovicová D, Kvetnanský R, Zeman M. Rhythmic clock gene expression in heart, kidney and some brain nuclei involved in blood pressure control in hypertensive TGR(mREN-2)27 rats. Mol Cell Biochem. 2007; 296(1-2):25-34.

Hill, WC. Primates: comparative anatomy and taxonomy. Edinburgh, UK: Edinburgh at the University Press; 1962. v. 5, pt. B, 537 p.

Hisano S, Chikamori-Aoyama M, Katoh S, Kagotani Y, Daikoku S, Chihara K. Suprachiasmatic nucleus neurons immunoreactive for vasoactive intestinal polypeptide have synaptic contacts with axons immunoreactive for neuropeptide $\mathrm{Y}$ : an immunoelectron microscopic study in the rat. Neurosci Lett. 1988;88(2):145-50.

Ibata Y, Takahashi Y, Okamura H, Kawakami F, Terubayashi H, Kubo T, Yanaihara N. Vasoactive intestinal peptide (VIP)-like immunoreactive neurons located in the rat suprachiasmatic nucleus receive a direct retinal projection. Neurosci Lett. 1989;97(1-2):15 .

Ibata Y, Tanaka M, Ichitani Y, Takahashi Y, Okamura H. Neuronal interaction between VIP and vasopressin neurones in the rat suprachiasmatic nucleus. Neuroreport. 1993; $4(2): 128-30$.

Inouye ST, Kawamura H. Persistence of circadian rhythmicity in a mammalian hypothalamic "islan" containing the suprachiasmatic nucleus. Proc Natl Acad. 1979;76: 5962-66

Johnson AL, Tilly JL. Effects of vasoactive intestinal peptide on steroid secretion and plasminogen activator activity in granulosa cells of the hen. Biol Reprod. 1988;38(2):296303.

Johnson RF, Morin LP, Moore RY. Retinohypothalamic projections in hamster and rat demonstrated using cholera toxin. Brain Res. 1988;462:301-12. 
Kaas JH, Huerta MF. The Subcortical Visual System of Primates. Comp. Primate Biol. 1988;4:327-391.

Kudo M, Yamamoto M, Nakamura Y. Suprachiasmatic nucleus and retinohypothalamic projections in moles. Brain Behav Evol. 1991;38(6):332-8.

Kumar SS, Buckmaster PS. Neuron-specific nuclear antigen NeuN is not detectable in gerbil subtantia nigra pars reticulata. Brain Res. 2007;1142:54-60.

Larsen PJ, Jessop DS, Chowdrey HS, Mikkelsen JD, Lightman SL. (1992) Osmotic regulation of substance $\mathrm{P}$ and neurokinin A peptide content and substance $\mathrm{P}$ binding sites in distinct hypothalamic nuclei of the rat. Peptides. 1992;13(4):705-12.

Lehman MN, Silver R, Gladstone WR, Kahn RM, Gibson M, Bittman EL. Circadian rhythmicity restored by neural transplant. Immunocytochemical characterization of the graf and its integration with the host brain, J Neurosci. 1987;7(6):1626-38.

LeSauter J, Kriegsfeld LJ, Hon J, Silver R. Calbindin-D28K cells selectively contact intraSCN neurons. Neuroscience. 2002;111:575-85.

LeSauter J, Silver R. Localization of a suprachiasmatic nucleus subregion regulating locomotor rhythmicity. J Neurosci. 1999;19(13):5574-85.

Levine JD, Weiss ML, Rosenwasser AM, Miselis RR. Retinohypothalamic tract in the female albino rat: a study using horseradish peroxidase conjugated to cholera toxin. $\mathbf{J}$ Comp Neurol. 1991;306:344-60.

Ling C, Schneider GE, Jhaveri S. Target-specific morphology of retinal axon arbors in the adult hamster. Vis Neurosci. 1998;15(3):559-79.

Mai JK, Kedziora O, Teckhaus L, Sofroniew MV. Evidence for subdivisions in the human suprachiasmatic nucleus. J Comp Neurol. 1991;305:508-25.

Marques N, Menna-Barreto L. Cronobiologia: princípios e aplicações. 3. ed. rev. e ampl. São Paulo: Editora da Universidade de São Paulo; 2003. 
Martinet L, Bonnefond C, Peytevin J, Monnerie R, Marcilloux JC. Vasoactive intestinal polypeptide in the suprachiasmatic nucleus of the mink (Mustela vison) could play a key role in photic induction. J Neuroendocrinol. 1995;7:69-79.

Menaker M. Circadian photoreception. Science. 2003;299:213-4.

Miller JD, Morin LP, Schwartz WJ, Moore RY. New insights into the mammalian circadian clock. Sleep. 1996; 19:641-67.

Mittermeier RA. The world's endangered primates - An introduction and a case study the monkeys of Brazil's atlantic forests. World wildlife fund. - U.S. and the L.S.B. leakey foundation and the Tropical Forest. 1982;11-22

Mittermeier RA, Coimbra Filho AF. Primate Conservation. London: His Serene Highness Prince Rainier III; 1997.

Moore RY. Retinohypothalamic projection in mammals: a comparative study. Brain Res. 1973;49:403-9.

Moore RY. Organization and function of a central nervous system circadian oscillator: the suprachiasmatic hypothalamic nucleus. Fed. Proc. Am. Soc. Exp. Biol. 1983;42:2783-89.

Moore RY. The geniculohypothalamic tract in monkey and man. Brain Res. 1989; 486(1):190-4.

Moore RY. Organization of the primate circadian system. J Biol Rhythms. 1993;8 Suppl:S:3-9.

Moore RY. Circadian rhythms: basic neurobiology and clinical applications. Annu Rev Med. 1997;48:253-66.

Moore RY, Leak RK. Topographic organization of suprachiasmatic nucleus projection neurons, J Comp Neurol. 2001;433:312-34.

Moore RY, Lenn NJ. A retinohypothalamic projection in the rat. J Comp Neurol. 1972; 146:1-14. 
Moore RY, Speh JC. Serotonin innervation of the primate suprachiasmatic nucleus. Brain Res. 2004; 1010:169-73.

Moore RY, Gustafson EL, Card JP. Identical immunoreactivity of afferents to the rat suprachiasmatic nucleus with antisera against avian pancreatic polypeptide, molluscan cardioexcitatory peptide and neuropeptide Y. Cell Tissue Res. 1984;236(1):41-6.

Moore RY, Speh JC, Leak RK. Suprachiasmatic nucleus organization. Cell Tissue Res. 2002;309:89-98.

Moore RY. Organization of the primate circadian system. J Biol Rhythms. 1993;8 (Suppl):S3-9.

Moore RY. Organization of the mammalian circadian system. Ciba Found Symp. 1995; 183:88-99; 100-6.

Moore-Ede MC, Sulzman FM, Fuller CA. The clock that time us: physiology of the circadian timing system. Cambridge: Harvard University Press, 1982.

Morin LP. SCN organization reconsidered. J Biol Rhythms. 2007; 22:3-13.

Morin LP, Blanchard J, Moore RY. Intergeniculate leaflet and suprachiasmatic nucleus organization and connections in the golden hamster. Vis Neurosci. 1992;8:219-30.

Morin LP, Blanchard JH, Provencio I. Retinal ganglion cell projections to the hamster suprachiasmatic nucleus, intergeniculate leaflet and visual midbrain: bifurcation and melanopsin immunoreactivity. J Comp Neurol. 2003; 465:401-16.

Morin LP, Shivers KY, Blanchard JH, Muscat L. Complex organization of mouse and rat suprachiasmatic nucleus. Neuroscience. 2006;137:1285-97.

Mullen RJ, Buck CR, Smith AM. NeuN, a neuronal specific protein in vertebrates. Development. 1992;116(1):201-11. 
Murakami DM, Fuller CA. The retinohypothalamic projection and oxidative metabolism in the suprachiasmatic nucleus of primates and tree shrews. Brain Behav Evol. 1990; 35(5):302-12.

Muscat L, Huberman AD, Jordan CL, Morin LP. Crossed and uncrossed retinal projections to the hamster circadian system. J Comp Neurol. 2003; 466:513-24.

Nascimento Jr ES, Souza AP, Duarte RB, Magalhães MA, Silva SF, Cavalcante JC, Cavalcante JS, Costa MS. The suprachiasmatic nucleus and the intergeniculate leaflet in the rock cavy (Kerodon rupestris): retinal projections and immunohistochemical characterization. Brain Res. 2010;1320:34-46.

Negroni J, Bennett NC, Cooper HM. Organization of the circadian system in the subterranean mole rat, Cryptomys hottentotus (Bathyergidae). Brain Res. 2003;967:48-62.

Newman GC, Hospod FE. Rhythm of suprachiasmatic nucleus 2-deoxyglucose uptake in vitro. Brain Res. 1986;381(2):345-50.

Oppenheimer JR. Behavior and ecology of the White faced monkey, Cebus capucinus, on Barro Colorado Island. [tese (Doutorado)]. University of Illinois; 1981.

Piggins HD, Cutler DJ, Rusak B. Ionophoretically applied substance P activates hamster suprachiasmatic nucleus neurons. Brain Res Bull. 1995;37(5):475-9.

Pinato L, Allemandi W, Abe LK, Frazão R, Cruz-Rizzolo RJ, Cavalcante JS. A comparative study of cytoarchitecture and serotonergic afferents in the suprachiasmatic nucleus of primates (Cebus apella and Callithrix jacchus) and rats (Wistar and Lond Evans strain). Brain Res. 2007;1149:101-10.

Pinato L, Frazão R, Cruz-Rizzolo RJ, Cavalcante JS, Nogueira MI. Immunocytochemical characterization of the pregeniculate nucleus and distribution of retinal and neuropeptide $\mathrm{Y}$ terminals in the suprachiasmatic nucleus of the Cebus monkey. J Chem Neuroanat. 2009; 37(4):207-13.

Quintero JE, Kuhlman SJ, McMahon DG. The biological clock nucleus: a multiphasic oscillator network regulated by light. J Neurosci. 2003;23:8070-6. 
Ralph MR, Foster RG, Davis FC, Menaker M. Transplanted suprachiasmatic nucleus determines circadian period. Science. 1990;274(4945):975-8.

Reuss S, Bürger K. Substance P-like immunoreactivity in the hypothalamic suprachiasmatic nucleus of Phodopus sungorus--relation to daytime, photoperiod, sex and age. Brain Res. 1994; 638(1-2):189-95.

Reuss S, Decker K, Hödl P, Sraka S. Anterograde neuronal tracing of retinohypothalamic projections in the hamster--possible innervation of substance P-containing neurons in the suprachiasmatic nucleus. Neurosci Lett. 1994;174(1):51-4.

Reuss S, Hurlbut EC, Speh JC, Moore RY. Immunohistochemical evidence for the presence of neuropeptides in the hypothalamic suprachiasmatic nucleus of ground squirrels. Anat Rec. 1989;225:341-46.

Saeb-Parsy K and Dyball RE. Defined cell groups in the rat suprachiasmatic nucleus have different day/night rhythms of single-unit activity in vivo. J Biol Rhythms. 2003;18:26-42.

Sarnat HB, Nochlin D, Born DE. Neuronal nuclear antigen (NeuN): a marker of neuronal maturation in early human fetal nervous system. Brain Dev. 1998;20(2):88-94.

Schaap J, Albus H, Eilers PH, Detari L, Meijer JH. Phase differences in electrical discharge rhythms between neuronal populations of the left and right suprachiasmatic nuclei. Neuroscience. 2001; 108:359-63.

Schaap J, Albus H, Eilers PH, Detari L, Meijer JH. Phase differences in electrical discharge rhythms between neuronal populations of the left and right suprachiasmatic nuclei. Neuroscience. 2001;108:359-63.

Sehgal A Molecular biology of circadian rhythms. Hoboken, NJ. Wiley-Liss; 2004.

Shearman LP, Zylka MJ, Weaver DR, Kolakowski Jr LF, Reppert SM. Two period homologs: circadian expression and photic regulation in the suprachiasmatic nuclei. Neuron. 1997;19(6):1261-9.

Shen H, Semba K. A direct retinial projection to the dorsal raphe nucleus in the rat. Brain Res. 1994;(1-2):159-68. 
Shieh KR, Yang SC, Lu XY, Akil H, Watson SJ. Diurnal rhythmic expression of the rhythm-related genes, rPeriod1, rPeriod2, and rClock, in the rat brain. J Biomed Sci. 2005; 12(1):209-17.

Shinohara K, Tominaga K, Isobe Y, Inouye ST. Photic regulation of peptides located in the ventrolateral subdivision of the suprachiasmatic nucleus of the rat: daily variations of vasoactive intestinal polypeptide, gastrin-releasing peptide, and neuropeptide Y. J Neurosci. 1993;13(2):793-800.

Silver R, LeSauter J, Tresco PA, Lehman MN. A diffusible coupling signal from the transplanted suprachiasmatic nucleus controlling circadian locomotor rhythms. Nature. $1996 ; 382: 810-3$.

Silver R, Sookhoo AI, LeSauter J, Stevens P, Jansen HT, Lehman MN. Multiple regulatory elements result in regional specificity in circadian rhythms of neuropeptide expression in mouse SCN. Neuroreport. 1999;10:3165-74.

Smale L, Blanchard JH, Moore RY, Morin LP. Immunocytochemical characterization of the suprachiasmatic nucleus and the intergeniculate leaflet in the diurnal ground squirrel, Spermophilus lateralis. Brain Res. 1991;563:77-86.

Smale L, Boverhof J. The suprachiasmatic nucleus and intergeniculate leaflet of Arvicanthis niloticus, a diurnal murid rodent from East Africa. J Comp Neurol. 1999; 403(2):190-208.

Stephan FK, Zucker I. Circadian rhythms in drinking behavior and locomotor activity of rats are eliminated by hypothalamic lesions. Proc Natl Acad Sci USA. 1972;69:1583-6.

Takatsuji K, Miguel-Hidalgo JJ, Tohyama M. Substance P-immunoreactive innervation from the retina to the suprachiasmatic nucleus in the rat. Brain Res. 1991;568(1-2):223-9.

Takumi T, Matsubara C, Shigeyoshi Y, Taguchi K, Yagita K, Maebayashi Y, Sakakida Y, Okumura K, Takashima N, Okamura H. A new mammalian period gene predominantly expressed in the suprachiasmatic nucleus. Genes Cells. 1998;3(3):167-76.

Tominaga K, Shibata S, Ueki S, Watanabe S. Effects of 5-HT, agonists on the circadian rhythm in wheel running activity in hamsters. Eur J Pharmacol. 1992;214:79-84. 
Van den Pol AN, Tsujimoto KL. Neurotransmitters of the hypothalamic suprachiasmatic nucleus: immunocytochemical analysis of 25 neuronal antigens. Neuroscience. 1995; 15(4):1049-86.

Van den Pol AN. The hypothalamic suprachiasmatic nucleus of rat: intrinsic anatomy. J Comp Neurol. 1980;191(4):661-702.

Verderane MP, Neves PM, Izar P. O cuidado aleitamento materno exibido por uma fêmea de macaco-prego (Cebus apella) de um grupo semilivre do Parque Ecológico do Tietê, S.P., após a morte da própria cria: um caso de adoção? XI Congresso Brasileiro de Primatologia; 2005; Porto Alegre: PUC-RS; 2005. p. 175.

Weyer A, Schilling K. Developmental and cell type-specific expression of the neuronal marker NeuN in the murine cerebellum. J Neurosci Res. 2003;73(3):400-9.

Youngstrom TG, Weiss ML, Nunez AA. Retinofugal projections to the hypothalamus, anterior thalamus and basal forebrain in hamsters. Brain Res Bull. 1991;26:403-11. 